\title{
Micro-level Estimation of Optimal Consumption Choice With Intertemporal Nonseparability in Preferences and Measurement Errors
}

\author{
Gayle, Wayne-Roy; Khorunzhina, Natalia
}

Document Version

Accepted author manuscript

Published in:

Journal of Business and Economic Statistics

DOI:

$10.1080 / 07350015.2016 .1149071$

Publication date:

2018

License

Unspecified

Citation for published version (APA):

Gayle, W-R., \& Khorunzhina, N. (2018). Micro-level Estimation of Optimal Consumption Choice With

Intertemporal Nonseparability in Preferences and Measurement Errors. Journal of Business and Economic Statistics, 36(2), 227-238. https://doi.org/10.1080/07350015.2016.1149071

Link to publication in CBS Research Portal

\section{General rights}

Copyright and moral rights for the publications made accessible in the public portal are retained by the authors and/or other copyright owners and it is a condition of accessing publications that users recognise and abide by the legal requirements associated with these rights.

\section{Take down policy}

If you believe that this document breaches copyright please contact us (research.lib@cbs.dk) providing details, and we will remove access to the work immediately and investigate your claim.

Download date: 26. Apr. 2023

$$
\text { EQUIS }
$$

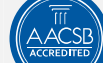




\title{
Micro-level Estimation of Optimal Consumption Choice With Intertemporal Nonseparability in Preferences and Measurement Errors
}

\author{
Wayne-Roy Gayle and Natalia Khorunzhina
}

Journal article (Accepted manuscript*)

\section{Please cite this article as:}

Gayle, W-R., \& Khorunzhina, N. (2018). Micro-level Estimation of Optimal Consumption Choice With Intertemporal Nonseparability in Preferences and Measurement Errors. Journal of Business and Economic Statistics, 362), 227-238. 001: 10.1080/07350015.2016.1149071

This is an Accepted Manuscript of an article published by Taylor \& Francis in Journal of Business and Economic Statistics on 27 Apr २०17, available online:

DOl: http://www.tandfonline.com/10.1080/07350015.2016.1149071

* This version of the article has been accepted for publication and undergone full peer review but has not been through the copyediting, typesetting, pagination and proofreading process, which may lead to differences between this version and the publisher's final version AKA Version of Record. 


\title{
Micro-level Estimation of Optimal Consumption Choice with Intertemporal Nonseparability in Preferences and Measurement Errors
}

\author{
Wayne-Roy Gayle \\ Department of Resource Economics, University of Massachusetts, \\ Stockbridge Hall, Amherst MA, USA (wayneroy@umass.edu) \\ and \\ Natalia Khorunzhina \\ Department of Economics, Copenhagen Business School, \\ Porcelænshaven 16A, 2000 Frederiksberg, Denmark (nk.eco@cbs.dk) \\ January 13, 2016
}

\begin{abstract}
This paper investigates the presence of habit formation in household consumption, using data from the Panel Study of Income Dynamics. We develop an econometric model of internal habit formation of the multiplicative specification. The restrictions of the model allow for classical measurement errors in consumption without parametric assumptions on the distribution of measurement errors. We estimate the parameters by nonlinear generalized method of moments and find that habit formation is an important determinant of household foodconsumption patterns. Using the parameter estimates, we develop bounds for the expectation of the implied heterogeneous intertemporal elasticity of substitution and relative risk aversion that account for measurement errors, and compute confidence intervals for these bounds.
\end{abstract}

Keywords: Habit formation; Nonlinear models; Intertemporal elasticity of substitution; Relative risk aversion.

JEL C13, C33, C51, D12, D91 


\section{INTRODUCTION}

Since the early 1980s, a growing body of literature has recognized the potential for intertemporal nonseparabilities in preferences to address a variety of stylized facts in economics. The success of these nonseparability specifications has led economists to investigate their empirical validity. For the majority of empirical studies, habit formation is the dominant specification of intertemporal nonseparability in preferences, and consumption is the dominant economic process studied. Whereas aggregated consumption data largely support habit formation (e.g., Ferson and Constantinides 1991; Heaton 1995; Fuhrer 2000; Chen and Ludvigson 2009; Smith and Zhang 2007), the literature on testing for the existence of habit formation using micro data is sparse and inconclusive. The studies of Carrasco, Labeaga, and Lopez-Salido (2005) and Browning and Collado (2007) find support for habit formation in individual consumption, whereas those of Meghir and Weber (1996) and Dynan (2000) do not. Yet, if it exists, habit formation leads to a number of important quantitative and qualitative implications for the intertemporal elasticity of substitution (IES) and relative risk aversion (RRA). Habit-forming preferences generate smaller IES and larger RRA than their counterparts generated by time-separable utility specifications (Constantinides 1990; Campbell and Cochrane 1999). Habit formation in preferences can also generate individual heterogeneity in the IES and RRA through their dependencies on past consumption experience, where the level of dependence is governed by the strength of habit formation.

In this paper, we empirically investigate the presence of internal habit formation in household food consumption using data from the Panel Study of Income Dynamics (PSID). We exploit the structure of the implied Euler equation to develop a nonlinear generalized method of moments (GMM) estimator that accounts for classical measurement errors in observed consumption. The theoretical restrictions of our model allow us to do so without imposing parametric restrictions on the distribution of measurement errors. We prove identification and estimate all preference parameters, including the strength of habit formation. We derive the IES and RRA that are implied from our model specification and use our estimated parameters to investigate the magnitudes and individual variations in these key economic quantities.

We construct the estimator under the assumption that habit formation takes a multiplicative (or ratio) form introduced in Abel (1990), where consumption services are given by $C_{t} / C_{t-1}^{\alpha}$. The main alternative to this specification is the difference model of habit, where consumption services 
are given by, for example, $C_{t}-\alpha C_{t-1}$. Two related points motivate the choice of the multiplicative specification. First, individual consumption data are more volatile than aggregate consumption data. As a result, whereas the restriction of positive consumption services is relatively easy to satisfy in difference models when using aggregated data, it is likely to be violated when using micro data. The multiplicative specification of consumption services satisfies the positivity constraint on consumption services for any pair $\left(C_{t}, C_{t-1}\right)$, thus making it more appropriate when using micro-data. Second, a fraction of the volatility in observed consumption may be due to the existence of measurement errors. Under the multiplicative specification, the resulting econometric model derived from the consumption Euler equation allows for classical measurement errors in consumption without imposing parametric assumptions on their distribution. Our nonlinear GMM estimator extends Alan, Attanasio, and Browning (2009), who propose two exact nonlinear GMM estimators for the consumption Euler equation without intertemporal nonseparability in preferences. To the best of our knowledge, this paper presents the first exact Euler equation nonlinear GMM method that is developed to investigate the existence of habit formation without imposing parametric assumptions on the distribution of measurement errors. The empirical results suggest habit formation is an important determinant of food-consumption patterns. We also find the estimates of the structural parameters are robust across various specifications, and ignoring measurement errors significantly weakens the evidence of habit formation.

Our approach to investigating the heterogeneity in the intertemporal elasticity of substitution and relative risk aversion implied by habit-forming preferences constitutes another novelty of the paper. The literature uses other methods, where the dominant approach in evaluating heterogeneity in the RRA and IES is to apply iso-elastic utility models to different economic units (e.g., Attanasio and Weber 1993; Vissing-Jorgenssen 2002; Crossley and Low 2011). The advantage of our approach is that in habit-formation frameworks, individual- and time-varying IES and RRA are determined by preference parameters that are not functions of the economic environment, thus making these models more suitable for counterfactual policy analysis. However, unlike the preference parameters of the model, the conditional expectations of the IES and RRA are not point identified when observed consumption is contaminated by measurement errors, even when the distribution of measurement errors is parameterized. To facilitate the inference, we develop bounds on the conditional expectations of the IES and RRA that allow for measurement errors 
in observed consumption. We construct confidence intervals for these bounds using the method developed in Chernozhukov, Hong, and Tamer (2007). Although these bounds are not sharp, they are informative for investigating the level of biasedness introduced by the assumption of log-normal measurement errors, an assumption often imposed in the literature. In particular, we find the $95 \%$ confidence interval for the unconditional expectation of the IES is [0.06, 0.11], and the corresponding 95\% confidence interval for the unconditional expectation of the RRA is [9.4, 15.5]. The corresponding confidence intervals of the IES and RRA under the assumption of lognormally distributed measurement errors are $[0.11,0.15]$ and $[6.6,9.0]$, respectively. The finding that the confidence intervals do not overlap suggests the log-normality assumption on measurement errors in observed consumption may be too strong. We find the constructed $95 \%$ confidence intervals for the bounds on the expectations of the IES and RRA conditioned on education, age, income groups, and family size are not informative for investigating heterogeneity in the IES and RRA.

The remainder of the paper is as follows. Section 2 sets up the theoretical model. Section 3 develops the econometric model. Section 4 discusses identification of the parameters of interest, and section 5 provides the definition of the estimator, outlines asymptotic properties, and discusses the small-sample properties. Section 6 describes the data sample used in estimation. Section 7 presents the empirical results, and section 8 examines the implications for the relative risk aversion and intertemporal elasticity of substitution. Section 9 concludes. The proofs and detailed derivations are presented in the Appendix.

\section{THEORETICAL FRAMEWORK}

Household $i$ chooses a sequence of consumption $\left\{C_{i s}, s=t, \cdots, T\right\}$ to maximize its expected lifetime utility, given by

$$
E_{i t} \sum_{s=t}^{T} \beta^{s-t} \phi_{i s} \frac{\tilde{C}_{i s}^{1-\gamma}-1}{1-\gamma}
$$

where the expectation is conditional on all information relevant to household $i$ at time $t, \beta \in(0,1)$ is the time-discount factor, $\gamma$ is the utility curvature parameter, and $\tilde{C}_{i t}$ denotes consumption services in period $t$. Consumption services are defined as the geometrically weighted ratio of 
current consumption expenditures to past consumption expenditures,

$$
\tilde{C}_{i t}=\frac{C_{i t}}{C_{i t-1}^{\alpha}}
$$

where $0 \leq \alpha \leq 1$ measures the strength of habits, with $\alpha=1$ denoting the strongest habit and $\alpha=0$ indicating no habit in consumption. This habit-formation specification was originally introduced by Abel (1990), and further used, among others, in a general theoretical analysis of the preferences in Caroll (2000), in theoretical justification of growth-to-savings causation by Caroll, Overland, and Weil (2000), and for empirical analysis with aggregate data by Smith and Zhang (2007). The main alternative to this specification is the difference model of habit formation used in Ferson and Constantinides (1991), Heaton (1995), Campbell and Cochrane (1999), Dynan (2000), and Chen and Ludvigson (2009), among others. In this case, consumption services are given by, for example, $\tilde{C}_{t}=C_{t}-\alpha C_{t-1}$ with analogous restrictions on the habitformation parameter $\alpha$.

The household-specific taste shifters $\phi_{i t}$ affect the household's utility (2.1). Researchers have widely accepted the importance of augmenting the individual utility function with individualspecific taste shifters in the estimation of optimal consumption choices using micro data (Banks, Blundell, and Tanner 1998; Attanasio, Banks, Meghir and Weber 1999; Dynan 2000; Alan, Attanasio, and Browning 2009). Household-specific taste shifters $\phi_{i t}$ are given by

$$
\phi_{i t}=\exp \left(\delta w_{i t}+\omega_{i}\right)
$$

where $w_{i t} \in \mathcal{W} \in \mathfrak{R}^{d_{w}}$ is the $d_{w}$-dimensional vector of exogenous time-varying observed household characteristics and $\omega_{i}$ is a household fixed effect.

We assume household $i$ is not subject to a liquidity constraint and has rational expectations. The first-order necessary condition for the household's optimization problem is

$$
E\left[\beta\left(1+r_{i t+1}\right) M U_{i t+1}-M U_{i t} \mid z_{i t}\right]=0,
$$

where $r_{i t+1}$ is the rate of return on savings of household $i$ between periods $t$ and $t+1, z_{i t}$ denotes 
the set of all information that is available to household $i$ at time $t$, and $M U_{i t}$ is given by

$$
M U_{i t}=\frac{\phi_{i t}}{C_{i t}}\left(\frac{C_{i t}}{C_{i t-1}^{\alpha}}\right)^{1-\gamma}-\alpha \beta \frac{\phi_{i t+1}}{C_{i t}}\left(\frac{C_{i t+1}}{C_{i t}^{\alpha}}\right)^{1-\gamma}
$$

Note that if $\alpha=0, M U_{i t}$ in equation (2.3) reduces to the marginal utility of time-separable models. For $\alpha>0$, consumption services are negatively related to past consumption levels. This property is shared with difference models of habit formation. However, in the case of the multiplicative model, $\alpha>0$ is not sufficient to characterize habit formation. The multiplicative model also requires $\gamma>1$ for preferences to exhibit habit formation. Indeed, as long as both $\alpha>0$ and $\gamma>1$, the household's marginal utility of consumption in period $t$ is an increasing function of period $t-1$ consumption, yielding complementarity in consumption over time (Constantinides 1990; Heaton 1995; Kocherlakota 1996).

Substituting equation (2.3) into equation (2.2) obtains the following consumption Euler equation:

$$
E\left[\beta\left(1+r_{i t+1}\right)\left(\frac{\phi_{i t+1}}{C_{i t+1}}\left(\frac{C_{i t+1}}{C_{i t}^{\alpha}}\right)^{1-\gamma}-\alpha \beta \frac{\phi_{i t+2}}{C_{i t+1}}\left(\frac{C_{i t+2}}{C_{i t+1}^{\alpha}}\right)^{1-\gamma}\right)-\frac{\phi_{i t}}{C_{i t}}\left(\frac{C_{i t}}{C_{i t-1}^{\alpha}}\right)^{1-\gamma}+\alpha \beta \frac{\phi_{i t+1}}{C_{i t}}\left(\frac{C_{i t+1}}{C_{i t}^{\alpha}}\right)^{1-\gamma} \mid z_{i t}\right]=0 .
$$

\section{ECONOMETRIC MODEL}

To derive an estimator for the parameters of interest from equation (2.4), we address two key issues: potential household-specific effects in preferences, and measurement errors in consumption.

\subsection{Consumption growth}

Transforming the Euler equation (2.4) into the one expressed in terms of consumption growth instead of levels has several advantages. Consumption growth may be stationary even though consumption is not. Habit formation in consumption generates positive serial correlation in consumption over time, as does household-specific heterogeneity in preferences. As a result, not accounting for household-specific heterogeneity in preferences will bias the estimates in favor of finding evidence of habit formation. The transformation of equation (2.4) into consumption 
growth rates eliminates unobserved household-specific effects in the taste shifters, $\omega_{i}$. Furthermore, the growth-rate transformation allows for weaker conditions on the distribution of measurement errors, a point we address in the next section.

Let $c_{i t}=C_{i t} / C_{i t-1}$, and $\varphi_{i t}=\phi_{i t} / \phi_{i t-1}=\exp \left(\delta \Delta w_{i t}\right)$. Because $C_{i t}, C_{i t-1}, w_{i t}$, and $\omega_{i}$ are known to household $i$ in period $t$, so is $\left(\phi_{i t} / C_{i t}\right)\left(C_{i t} / C_{i t-1}^{\alpha}\right)^{1-\gamma}$, which is strictly positive for all values of $C_{i t}, C_{i t-1}, w_{i t}$, and $\omega_{i}$. Thus, dividing equation (2.4) by this quantity leads to

$$
E\left[\beta\left(1+r_{i t+1}\right) \frac{\varphi_{i t+1}}{c_{i t+1}}\left(\frac{c_{i t+1}}{c_{i t}^{\alpha}}\right)^{1-\gamma}\left(1-\alpha \beta \varphi_{i t+2}\left(\frac{c_{i t+2}}{c_{i t+1}^{\alpha}}\right)^{1-\gamma}\right)-\left(1-\alpha \beta \varphi_{i t+1}\left(\frac{c_{i t+1}}{c_{i t}^{\alpha}}\right)^{1-\gamma}\right) \mid z_{i t}\right]=0 .
$$

\subsection{Measurement error}

Given a set of appropriate instruments and the absence of measurement errors, consistent estimators of the parameters $\alpha, \beta, \gamma$, and $\delta$ can be obtained based on the moment condition in equation (3.1). However, the estimation of nonlinear rational-expectations models using micro data is complicated by the problem of measurement errors in consumption, which, if ignored, will likely result in inconsistent estimation of the key parameters of interest.

Define $z_{i t}^{o}$ to be a subset of the information set available to household $i$ in period $t$ and observable to the econometrician. Then, by the law of iterated expectations, equation (3.1) implies

$$
E\left[\beta\left(1+r_{i t+1}\right) \frac{\varphi_{i t+1}}{c_{i t+1}}\left(\frac{c_{i t+1}}{c_{i t}^{\alpha}}\right)^{1-\gamma}\left(1-\alpha \beta \varphi_{i t+2}\left(\frac{c_{i t+2}}{c_{i t+1}^{\alpha}}\right)^{1-\gamma}\right)-\left(1-\alpha \beta \varphi_{i t+1}\left(\frac{c_{i t+1}}{c_{i t}^{\alpha}}\right)^{1-\gamma}\right) \mid z_{i t}^{o}\right]=0 .
$$

Let true consumption, $C_{i t}$, be measured with a multiplicative error, $\eta_{i t}$, so that observed consumption is given by $C_{i t}^{o}=C_{i t} \eta_{i t}$, where $\eta_{i t}>0$. Define $c_{i t}^{o}=C_{i t}^{o} / C_{i t-1}^{o}$ and $v_{i t}=\eta_{i t} / \eta_{i t-1}$, so that $c_{i t}^{o}=c_{i t} v_{i t}$. Define $x_{i t}^{t+2}=\left(r_{i t+1}, \Delta w_{i t+1}, \Delta w_{i t+2}, c_{i t}, c_{i t+1}, c_{i t+2}\right)$ and $v_{i t}^{t+2}=\left(v_{i t}, v_{i t+1}, v_{i t+2}\right)$. The following assumption imposes restrictions on the joint distribution of $\left(x_{i t}^{t+2}, v_{i t}^{t+2}, z_{i t}^{o}\right)$.

Assumption 3.1. For each household, $i$, and $t=2, \cdots, T-2, v_{i t}^{t+2}$ is stationary and independent from $x_{i t}^{t+2}$ and $z_{i t}^{o}$.

We maintain that neither $\left(c_{i 2}, \cdots, c_{i t}\right)$ nor $\left(v_{i 2}, \cdots, v_{i t}\right)$ are observable to the econometrician, and hence not subsets of $z_{i t}^{o}$. Therefore, the independence restriction of Assumption 3.1 requires that $\left(c_{i 2}^{o}, \cdots, c_{i t}^{o}\right)$ is not a subset of $z_{i t}^{o}$. Assuming the growth in measurement errors is independent of the growth in consumption, the first difference in taste shifters, and the rate of interest does not 
imply measurement errors are independent of consumption, taste shifters, and the rate of interest. For example, our independence assumption allows for permanent unobservables in measurement errors that occur if some individuals persistently under- or over-report their levels of consumption (by the same amount). The assumption also allows for this tendency to under- or over-report to be correlated with other factors such as income. The stationarity restriction of Assumption 3.1 does not imply $\eta_{i t}$ is stationary. It allows for some (but not all) forms of time trends in reporting consumption, such as the case in which the bias in the reported consumption decreases over time because of experience in reporting. The stationarity assumption also allows for serial correlation in the mistakes made in reporting consumption expenditures, which occur if the respondent has a tendency to over-correct past mistakes.

The following theorem states that under Assumption 3.1, the moment condition in equation (3.2) can be transformed into a moment condition expressed in terms of the observed consumption growth.

Theorem 3.2. Suppose Assumption 3.1 is satisfied; then positive constants $\mathcal{A}_{1}, \mathcal{A}_{2}$, and $\mathcal{A}_{3}$ exist such that equation (3.2) implies

$$
E\left[\beta\left(1+r_{i t+1}\right) \frac{\varphi_{i t+1}}{c_{i t+1}^{o}}\left(\frac{c_{i t+1}^{o}}{c_{i t}^{o \alpha}}\right)^{1-\gamma}\left(\mathcal{A}_{1}^{-1}-\alpha \beta \mathcal{A}_{2}^{-1} \varphi_{i t+2}\left(\frac{c_{i t+2}^{o}}{c_{i t+1}^{o \alpha}}\right)^{1-\gamma}\right)-\left(1-\alpha \beta \mathcal{A}_{3}^{-1} \varphi_{i t+1}\left(\frac{c_{i t+1}^{o}}{c_{i t}^{o \alpha}}\right)^{1-\gamma}\right) \mid z_{i t}^{o}\right]=0,
$$

where

$$
\begin{aligned}
& \mathcal{A}_{1}=E\left[\frac{1}{v_{i t+1}}\left(\frac{v_{i t+1}}{v_{i t}^{\alpha}}\right)^{1-\gamma}\right], \\
& \mathcal{A}_{2}=E\left[\frac{1}{v_{i t+1}}\left(\frac{v_{i t+1} v_{i t+2}}{\left(v_{i t} v_{i t+1}\right)^{\alpha}}\right)^{1-\gamma}\right], \text { and } \\
& \mathcal{A}_{3}=E\left[\left(\frac{v_{i t+1}}{v_{i t}^{\alpha}}\right)^{1-\gamma}\right] .
\end{aligned}
$$

Proof. See Appendix A.

Equation (3.3) is the main equation of interest in this paper. It forms the basis of estimating the preference parameters of the model without imposing distributional assumptions on $\eta$. The three additional parameters, $\mathcal{A}_{1}, \mathcal{A}_{2}$, and $\mathcal{A}_{3}$, in equation (3.3) rescale the terms in the Euler equation expressed in terms of observed consumption growth to equate them to the terms in the 
true Euler equation (3.2). This transformation relies on the multiplicative and power-function representation of the habit-formation component in consumption services, and is not directly applicable if the difference specification of habit formation is assumed. However, as discussed in the introduction, the multiplicative specification of habit formation is more appropriate for investigating habit formation in micro data because, unlike the difference specification, consumption services are always positive. Furthermore, as discussed in the previous section, theoretical and empirical investigations of intertemporal nonseparabilities in consumption often assume multiplicative habit formation. The parameters, $\mathcal{A}_{1}, \mathcal{A}_{2}$, and $\mathcal{A}_{3}$, are functions of the joint distribution of $v_{i t}^{t+2}$, the curvature parameter, $\gamma$, and the habit-formation parameter, $\alpha$. Without parametric assumptions on the distribution of measurement errors, these terms do not have a closed-form representation and are treated as nuisance parameters to be estimated along with the preference parameters.

Estimation of the parameters of interest using equation (3.3) is not informative if one is interested in evaluating the variation in observed food consumption due to measurement errors, because the variance of measurement errors is not identified without additional assumptions. To this end, we will make the following functional-form assumption as an alternative specification:

Assumption 3.3. For each household, $i$, and for $t=1, \cdots, T$, the measurement errors in consumption are serially independent and log-normally distributed, $\ln \eta_{i t} \sim N\left(\mu_{i}, \sigma^{2}\right)$, and conditional on $\mu_{i}, \eta_{i t}$ is independent of $\left(r_{i s}, w_{i s}, C_{i s}, z_{i s}^{o}\right), s=1, \cdots, T$.

Equation (3.3) remains the same under the additional restriction of Assumption 3.3. However, under the parametric restriction of Assumption 3.3, direct calculation shows the constants $\mathcal{A}_{1}, \mathcal{A}_{2}$, and $\mathcal{A}_{3}$ in equation (3.4) take the following forms:

$$
\begin{aligned}
& \mathcal{A}_{1}=\exp \left\{\sigma^{2}\left(\alpha^{2}(1-\gamma)^{2}+\gamma^{2}-\alpha \gamma(1-\gamma)\right)\right\}, \\
& \mathcal{A}_{2}=\exp \left\{\sigma^{2}\left(\alpha^{2}(1-\gamma)^{2}+\gamma^{2}+(1-\gamma)(1+\alpha)\right)\right\}, \quad \text { and } \\
& \mathcal{A}_{3}=\exp \left\{\sigma^{2}\left(\left(1+\alpha+\alpha^{2}\right)(1-\gamma)^{2}\right)\right\} .
\end{aligned}
$$

We reiterate that identification and estimation of the preference parameters do not require functionalform restrictions on the distribution of the measurement errors. We impose Assumption 3.3 as an alternative specification in order to investigate the degree to which measurement errors ex- 
plain variation in observed consumption, and to analyze the degree of bias introduced by the log-normal measurement errors assumption.

\section{IDENTIFICATION}

In this section, we discuss identification of the structural parameters of the model: the timediscount factor, the utility curvature parameter, and the habit-formation parameter. We also discuss identification of the nuisance parameters introduced by measurement errors. Equation (3.3) is the focus of the analysis; however, we will also discuss identification of the variance of measurement errors, $\sigma^{2}$, under the functional-form restriction imposed by Assumption 3.3.

Define $c_{i t}^{o, t+2}=\left(c_{i t}^{o}, c_{i t+1}^{o}, c_{i t+2}^{o}\right), \tilde{c}_{i t}^{o, t+2}=\left(\ln c_{i t}^{o}, \ln c_{i t+1}^{o}, \ln c_{i t+2}^{o}\right), \Delta w_{i t+1}^{t+2}=\left(\Delta w_{i t+1}, \Delta w_{i t+2}\right)$, $x_{i t}^{o, t+2}=\left(r_{i t+1}, \Delta w_{i t+1}^{t+2}, c_{i t}^{o, t+2}\right)$, and $z_{i t}^{o}=\left(w_{i t}, z_{1 i t}^{o}\right)$, where $z_{1 i t}^{o}$ is a vector of "excluded" instruments. Let $\theta=\left(\gamma, \alpha, \delta, \beta, \mathcal{A}_{1}, \mathcal{A}_{2}, \mathcal{A}_{3}\right) \in \Theta$, and let the true parameter vector be $\theta_{0}=\left(\gamma_{0}, \alpha_{0}, \delta_{0}, \beta_{0}, \mathcal{A}_{10}\right.$, $\left.\mathcal{A}_{20}, \mathcal{A}_{30}\right) \in \Theta$. Under Assumption 3.3, let $\sigma_{0}^{2}$ be the true variance of measurement errors. Define also $\kappa_{1}=\mathcal{A}_{2} / \mathcal{A}_{1}, \kappa_{2}=\mathcal{A}_{2}, \kappa_{3}=\mathcal{A}_{2} / \mathcal{A}_{3}$, and

$$
\rho\left(x_{i t}^{o, t+2}, \theta\right)=\beta\left(1+r_{i t+1}\right) \frac{\varphi_{i t+1}}{c_{i t+1}^{o}}\left(\frac{c_{i t+1}^{o}}{c_{i t}^{o, \alpha}}\right)^{1-\gamma}\left(\kappa_{1}-\alpha \beta \varphi_{i t+2}\left(\frac{c_{i t+2}^{o}}{c_{i t+1}^{o, \alpha}}\right)^{1-\gamma}\right)-\left(\kappa_{2}-\alpha \beta \kappa_{3} \varphi_{i t+1}\left(\frac{c_{i t+1}^{o}}{c_{i t}^{o, \alpha}}\right)^{1-\gamma}\right) .
$$

Assumption 3.1 along with following assumption are sufficient for identification of $\theta_{0}$.

Assumption 4.1. ( $i) \Theta$ is compact and for at least one $t \in\{2, \cdots, T-2\}$ and for any measurable function $a\left(x_{i t}^{o, t+2}, z_{i t}^{o}\right), E\left[a\left(x_{i t}^{o, t+2}, z_{i t}^{o}\right) \mid z_{i t}^{o}\right]=0$ implies $a\left(x_{i t}^{o, t+2}, z_{i t}^{o}\right)=0$ almost surely.

(ii) For $t=2, \cdots, T-2, \operatorname{Rank}\left\{E\left[\left(1, r_{i t+1}, \Delta w_{i t+1}^{t+2}, \tilde{c}_{i t}^{o, t+2}\right)^{\prime}\left(1, r_{i t+1}, \Delta w_{i t+1}^{t+2}, \tilde{c}_{i t}^{o, t+2}\right)\right]\right\}=5+2 d_{w}$.

Assumption 4.1.i is completeness in $z_{1 i t}^{o}$ of the conditional distribution of $x_{i t}^{o, t+2}$ given $z_{i t}^{o}$ (see Newey and Powell 2003). The completeness assumption restricts the admissible families of conditional distributions that obtain identification of the parameters of the model. Note, however, the completeness assumption needs to hold only for one period in $\{2, \cdots, T-2\}$. Chen and Ludvigson (2009) used this assumption to identify the preference parameters in their semiparametric habit-based asset-pricing model. Chen, Chernozhukov, Lee, and Newey (2014) investigate identification of a model similar to Chen and Ludvigson (2009) using the weaker condition of bounded completeness. Bounded completeness is too weak to identify the parameters of our 
model, because observed consumption is not theoretically bounded, and $\rho\left(x_{i t}^{o, t+2}, \theta\right)$ in equation (4.1) is not bounded in observed consumption. Even if one is willing to assume true consumption is bounded, restricting observed consumption growth to a bounded set implicitly restricts the family of admissible distributions of measurement errors, which excludes typical distributions such as the log-normal distribution.

Assumption 4.1.ii is a rank condition that requires linearly independent variation in interest rates in period $t+1$ and the $\log$ of observed consumption growth over periods $t$ to $t+2$. This condition is satisfied in general by exogenous variation in interest rates, and household-timespecific shocks to true consumption, such as shocks to household income or wealth. Beyond the first difference in the taste shifters containing variation exogenous to consumption growth and interest rates, Assumption 4.1.ii implies the taste shifters cannot include the following: timeinvariant random variables, such as gender and race; random variables that change by a fixed amount over time, such as age and time; and random variables whose first differences are either constant over time or change by a fixed amount over time, such as age times education or age squared. Assumption 4.1.ii also excludes from taste shifters variables that are the same for all individuals in any given period of time, such as aggregate effects.

Identification of $\theta_{0}$ is stated in the following theorem.

Theorem 4.2. Suppose Assumptions 3.1 and 4.1 are satisfied. If $\alpha_{0}=0$, then $\left(\gamma_{0}, \alpha_{0}, \delta_{0}, \mathcal{A}_{10}^{-1} \beta_{0}\right.$, $\left.\mathcal{A}_{20}\right)$ is identified, and if Assumption 3.3 also holds, then $\left(\theta_{0}, \sigma_{0}^{2}\right)$ is identified. On the other hand, if $\alpha_{0}>0$, then $\theta_{0}$ is identified, and if in addition Assumption 3.3 holds, then $\sigma_{0}^{2}$ is also identified.

Proof. See Appendix B.

The intuition behind identification of the parameters in the habit-formation model is as follows. Internal habit formation links consumption in period $t-1$ to consumption in period $t+1$ in our period $t$ Euler equation in a similar way as two adjacent Euler conditions do in Alan, Attanasio, and Browning (2009). The term that links these observations of consumption over time is $\alpha_{0} \beta_{0}^{2}$, the product of the habit-formation parameter and the two-periods-ahead discount factor. The Euler equation also implies that because of habit formation, optimal consumption in period $t$ not only adjusts to shocks in the previous-period consumption, but also to anticipated shocks to the next-period consumption. The habit-formation parameter and the utility curvature parameter, $\gamma_{0}$, govern these rates of adjustments. Therefore, independent variation in period $t-1$ 
consumption, due to shocks to period $t-1$ interest rates and income, for example, and independent variation in period $t+1$ consumption identifies $\alpha_{0}$ and $\gamma_{0}$, which consequently identifies the discount factor. Independent variation in $\Delta w_{i t}$ identifies the parameters $\delta_{0}$, which govern the taste shifters. Given identification of the preference parameters, the nuisance parameters are identified from the discrepancy between rate of response of optimal true consumption to shocks in period $t$ interest rates and the corresponding rate of response of observed consumption. Finally, under Assumption 3.3, the only unknown term in $\mathcal{A}_{10}, \mathcal{A}_{20}$, and $\mathcal{A}_{30}$ defined in equation (3.5) is $\sigma_{0}^{2}$.

In time-separable models, failure to identify the discount factor separately from the measurement error term without distributional assumptions on measurement errors in consumption is a standard result (see a discussion in Alan, Attanasio, and Browning 2009). What is not standard in the literature is identifying the discount factor when specific distributional assumptions are imposed. Under no habit formation and log-normally distributed measurement errors, our estimator becomes similar to the estimator proposed by Ventura (1994). The additional source of identification in this paper relative to Ventura (1994) comes from the completeness assumption, which allows us to exploit variation in period $t+1$ interest rates to identify the variance of the distribution of measurement errors.

\section{THE ESTIMATOR: DEFINITION, ASYMPTOTIC, AND SMALL-SAMPLE PROPERTIES}

Define the $q$-dimensional vector $m_{i t}(\theta)=m\left(x_{i t}^{o, t+2}, z_{i t}^{o}, \theta\right)=z_{i t}^{o} \rho\left(x_{i t}^{o, t+2}, \theta\right)$, where $\rho\left(x_{i t}^{o, t+2}, \theta\right)$ is defined in equation (4.1), $q$ is a dimension of $z_{i t}^{o}$, and the corresponding $q(T-3)$-dimensional moment vector $m_{i}(\theta):=\left(m_{i 2}^{\prime}(\theta), \cdots, m_{i T-2}^{\prime}(\theta)\right)^{\prime}$. Then equation (3.3) implies

$$
m\left(\theta_{0}\right)=E\left[m_{i}\left(\theta_{0}\right)\right]=0
$$

Define $y_{i t}=\left(r_{i t}, w_{i t}, C_{i t}^{o}, z_{i t}^{o}\right)$ and $y_{i}=\left\{y_{i t}, t=1, \cdots, T\right\}$, and let $F_{y}$ be the joint distribution of $y_{i}$.

Assumption 5.1. A sample of $n$ independent realizations of $y$ are drawn from $F_{y}$. For each $i=1, \cdots, n, y_{i}$ is observed.

Let $\hat{m}(\theta):=\sum_{i=1}^{n} m_{i}(\theta) / n$ and $\hat{\Omega}(\theta):=\sum_{i=1}^{n} m_{i}(\theta) m_{i}^{\prime}(\theta) / n$. Then our estimator for the pa- 
rameters of interest $\hat{\theta}$ minimizes

$$
\hat{m}^{\prime}(\theta) \hat{\Omega}(\theta)^{+} \hat{m}(\theta)
$$

over $\Theta$, where $\hat{\Omega}(\theta)^{+}$is the generalized inverse of $\hat{\Omega}(\theta)$.

As suggested by Hansen, Heaton, and Yaron (1996), we apply continuous updating GMM (CUGMM) to obtain estimates of the structural parameters. Although CUGMM is known to be somewhat difficult to implement, it has the advantage of being pertinent. Note that by setting $\delta=0, \gamma=1$, and $\alpha \beta=\kappa_{1}=\kappa_{2} / \kappa_{3}$, the moment equation (5.1) is trivially satisfied. As Hansen, Heaton, and Yaron (1996) stated, CUGMM eliminates this trivial solution.

$$
\text { Let } M=E\left[\partial m_{i}\left(\theta_{0}\right) / \partial \theta\right], \Lambda=E\left[m_{i}\left(\theta_{0}\right) m_{i}\left(\theta_{0}\right)^{\prime}\right] \text {, and } \Sigma=\left(M^{\prime} \Lambda M\right)^{-1} \text {. }
$$

Theorem 5.2. Suppose the conditions of Theorem 4.2 and Assumption 5.1 are satisfied. Then $\hat{\theta} \stackrel{p}{\longrightarrow} \theta_{0}$, and $\sqrt{n}\left(\hat{\theta}-\theta_{0}\right) \stackrel{p}{\longrightarrow} N(0, \Sigma)$.

The proof of Theorem 5.2 is standard and not reproduced here. See Newey and McFadden (1994) for example.

In Appendix $\mathrm{C}$, we investigate the finite sample performance of the above estimator in recovering the parameters of interest. We also investigate the performance of the approximated log-linearized habit-formation model. The simulation exercise shows the proposed estimator performs well in recovering the parameters of interest, and that not accounting for measurement errors leads to underestimation of the discount factor and the strength of habits. The simulation exercise also shows that estimating the log-linearized version of the model (as opposed to the exact non-linear model) results in a significant downward bias in the estimate of $\alpha$ even without measurement errors in consumption.

\section{DATA}

Data on food consumption, income, and household demographic characteristics are available from the Panel Study of Income Dynamics (PSID). Although it is the longest panel study, and one of the most comprehensive sources of information for studying life-cycle processes, and poverty and welfare dynamics, its use for studying consumption involves one drawback: consumption data are available only for food. Fortunately, data on food consumption are particularly 
suitable for testing whether this category of consumption can be habit-forming, because food is a perishable good. The annual frequency of observation is also advantageous. Dynan (2000) argues that if durability has any effect on food consumption, it is not likely to last more than a few months.

Consumption of households consists of expenditures on food consumed at home, away from home, and the value of food stamps. Data on food consumed at home and the value of food stamps are deflated using the consumer price index (CPI) for food at home. Data on food consumed away from home are deflated using the CPI deflator for food away from home. All CPI data are taken from the CPI releases of the Bureau of Labor Statistics. Food-consumption data are deflated according to the month and year when the interview occurred, whereas food stamps and data on income are deflated using the CPI for the end of the year before the interview was conducted. In addition, total consumption expenditures are adjusted by the size of household using the square root of family members as a per-adult equivalence scale (for recent examples of this treatment, see Bick and Choi 2013, Guvenen and Smith 2014).

As in Shapiro (1984), Runkle (1991), and subsequent studies, we construct the householdspecific real after-tax interest rate as $r_{i t+1}=R_{t}\left(1-\tau_{i t+1}\right)-\pi_{t+1}$, where $R_{t}$ is the average 12month Treasury bill for the first half of the preceding year, $\tau_{i t+1}$ is the household marginal tax rate as reported in the PSID, and $\pi_{t+1}$ is the CPI deflator for the period of the interview.

To construct a data sample suitable for estimation of the model, we take observations on households from the nationally representative sample of households in the PSID covering 13 years from 1975 through 1987. The data availability motivates the time interval for the sample: the household marginal tax rate used in the construction of the household-specific real after-tax interest rate is only available after 1975, whereas data on food consumption are not available for several years after 1987. Our theoretical model applies to a liquidity-unconstrained household with no drastic household composition changes. Therefore, we apply the data-restriction criteria that the studies on estimation of life-cycle consumption models with the PSID routinely follow, including those previously referenced, such as Runkle (1991), Dynan (2000), and Alan, Attanasio, and Browning (2009).

From the PSID, we obtain an unbalanced panel of 3,182 households in which the head is between 22 and 65 years old, for whom consumption is available over at least four consecutive 
periods, and for which we have no missing observations on income and demographic characteristics such as family size and age. We exclude observations for which consumption grew by more than $300 \%$ or shrank by more than $66 \%$ from the previous period. The extreme outliers in consumption growth rate that we observe in the untrimmed data are likely due to measurement errors. Thus, the estimated magnitude of the variance of the measurement errors in consumption is to be considered a lower bound after this data trimming. We further exclude households whose marital status changed over the observed period, which leaves us with 2,507 households. Finally, to exclude liquidity-constrained households for whom the Euler equation (2.2) does not hold, we keep only the households that report positive savings over the sample period. With these restrictions, we have an unbalanced panel of 1,944 liquidity-unconstrained households covering 13 years from 1975 through 1987.

\section{EMPIRICAL RESULTS}

We address several issues while discussing the results obtained from the estimation. In particular, we examine the strength of habit formation in household consumption and the importance of accounting for measurement errors in consumption data. The main conclusions are that (i) habit formation plays an important role in explaining household food-consumption patterns, and (ii) not accounting for measurement errors in observed consumption results in a downward bias in the estimates of the habit-formation parameter and the discount factor.

Table 1 presents the estimation results for various specifications of the model. We report our main findings in columns (1) and (2), where column (1) shows the results for the baseline model and column (2) reports the results under the assumption of log-normal measurement errors in consumption. Recall that the habit-formation parameter alone is not sufficient to characterize habit formation; the multiplicative model of habit-formation requires that the curvature parameter $\gamma$ is greater than one for habit formation to exist. Both the baseline results and the results under the log-normality assumption in measurement errors show the estimate of $\gamma$ is significantly greater than one and the estimate of $\alpha$ is significantly greater than zero. The estimates of the baseline model and the model with parametric measurement errors support the existence of habit formation in household food consumption. Our estimates of the strength of habit formation compare well to the aggregate data estimates in the multiplicative habit-formation models. For example, 
Table 1: Estimation of the Euler equation with habit formation

\begin{tabular}{lcccc}
\hline Parameters & $\begin{array}{c}\text { Nonparametric ME } \\
(1)\end{array}$ & $\begin{array}{c}\text { Parametric ME } \\
(2)\end{array}$ & $\begin{array}{c}\text { Ignoring ME } \\
(3)\end{array}$ & $\begin{array}{c}\text { Approx.GMM } \\
(4)\end{array}$ \\
$\gamma$ & & & & \\
& 3.563 & 3.098 & 3.168 & \\
$\beta$ & $(0.404)$ & $(0.209)$ & $(0.217)$ & \\
& & & & \\
& 0.948 & 0.927 & 0.509 & \\
$\alpha$ & $(0.035)$ & $(0.043)$ & $(0.049)$ & \\
& & & & -0.190 \\
$\sigma^{2}$ & 0.761 & 0.747 & 0.213 & $(0.120)$ \\
& $(0.095)$ & $(0.082)$ & $(0.100)$ & \\
\hline$J$ statistic & & & & \\
$p$ value & 0.697 & 0.099 & & 0.000 \\
\hline
\end{tabular}

NOTE: Number of time periods $\mathrm{T}=13$, number of households $N=1,944$. The instrument set includes current and past Treasury bill rates (specific to the month and year of the PSID interview), family size, age of household head, and a constant. Standard errors are in parenthesis. The measurement error parameters $\mathcal{A}_{1}, \mathcal{A}_{2}$, and $\mathcal{A}_{3}$ for nonparametric measurement error specification in column (1) and the taste-shifter parameter $\delta$ on family size for all specifications are estimated but not reported. The full results are available from the authors upon request. For approximated GMM on column (4), the $F$ test for excluded instruments (dummies for lagged income and hours growth rates, and a dummy for whether the head of the household lost a job in previous period) is reported instead of the $J$-test. Here, seven households were lost due to missing observations on the dummy for whether the head of the household lost a job in previous period.

Fuhrer (2000) and Smith and Zhang (2007) estimate a habit-formation parameter between 0.80 and 1.04, which implies a somewhat stronger habit formation than the one found in our microdata estimation. Dynan (2000) indicates that serial correlation in aggregate consumption growth likely induces an upward bias in the estimates of the strength of habit formation. Our results suggest a substantial yet more moderate strength of habit formation in consumption compared to the findings with aggregate consumption data.

Relative to the baseline model, the point estimates of $\gamma, \beta$, and $\alpha$ are slightly smaller for the specification with log-normal measurement errors. The assumption of log-normal measurement errors allows us to evaluate the magnitude of the measurement-error contamination in the observed consumption, estimated as the variance of the measurement noise. The estimate of $\sigma^{2}$ is statistically significant and provides additional evidence of a substantial measurement-error issue 
in the observed consumption data, an empirical regularity originally quantified in Runkle (1991) and subsequently in empirical studies of Alan, Attanasio, and Browning (2009) and Alan and Browning (2010). Our estimate of noise in the observed consumption data suggests that about $53 \%$ of the variance of the observed log-consumption can be attributed to the measurement errors, which is consistent with the consensus that the PSID food-expenditure measure is considerably noisy.

For the remainder of this section, we discuss various specifications and robustness checks in order to investigate the reliability of our estimates. In particular, we investigate the bias introduced in our estimates when measurement errors are ignored, we investigate the performance of the log-linearized model in recovering the habit-formation parameter, and we discuss the effect of external habit, aggregate shocks, and intra-temporal nonseparabilites in preferences.

Columns (3) and (4) of Table 1 report the results of two additional model specifications. Column (3) presents the estimation results in which measurement errors in observed consumption data are ignored. Our estimation results using real data are complemented by investigating the issue of not accounting for measurement errors while they are present in the data, using the artificial data in the Monte Carlo experiment (see Appendix C). In this experiment, we contaminate consumption with the errors and estimate the model accounting for and ignoring the presence of measurement errors. The Monte Carlo experiment shows our estimator performs well when the measurement errors in consumption are present in the data and accounted for in estimation. At the same time, we also demonstrate that not accounting for measurement errors results in biased parameter estimates. The Monte Carlo experiment suggests that if measurement errors are ignored, the habit-formation parameter and the discount factor are estimated with downward biases. We conduct the same experiment with the real data, estimate equation (3.3) ignoring the presence of measurement errors in consumption, and report the results in column (3) of Table 1. Consistent with the Monte Carlo exercise, we find significant downward biases in the habit-formation parameter and the discount factor. In particular, the habit-formation parameter is only modestly significantly different from zero. Based on both the Monte Carlo experiment and the real data estimation, we can conclude that not accounting for measurement errors biases the results against finding habit formation in food consumption.

Column (4) of Table 1 reports the estimation results for the approximated log-linearized 
model of habit formation. The objective here is to investigate the performance of estimation based on the log-linear approximation to the Euler equation relative to the exact non-linear estimation method. We again complement our analysis by investigating the issue of log-linearization using the artificial data in the Monte Carlo experiment (see Appendix C). Hayashi (1985), Muellbauer (1988), and Dynan (2000) developed and estimated the linear approximation models of additive habit formation. Using assumptions of a constant interest rate and infinitely lived individuals, maintained in these studies, we derive a comparable estimator for the multiplicative habit-formation model (equation (C.1) in Appendix C) and estimate it using the two-stage instrumental variable estimator. Following Dynan (2000), our choice of instruments includes dummies for the ranges of lagged growth in income and hours worked, and a dummy for whether the head of the household lost a job in the previous period. The results in column (4) show the estimate of the habit-formation parameter is not significantly different from zero at the $5 \%$ level of significance. We conclude the estimates from the linearized model are biased against finding habit formation in food consumption. This finding is also consistent with the findings in the Monte Carlo experiment reported in Table 4 in Appendix C, where the habit-formation parameter is estimated with a large downward bias regardless of whether consumption is measured precisely or with errors. Overall, our findings indicate that in estimation, relying on the exact Euler equation is important, an assertion that Carroll (2001) also shares.

The estimates in Table 1 may be sensitive to various misspecifications of the baseline model for a number of reasons. We address three concerns that could influence the baseline estimates: internal habit versus external habit, the effect of aggregate shocks, and nonseparabilites in preferences over food and other consumption goods. We do not report the estimation results for these robustness checks, but they are available in the earlier versions of the paper and from the authors upon request.

The baseline model is specified to be consistent with habit being internal to the household: the household's period-specific utility depends on its past consumption and not the past consumption of others. As a robustness check, we incorporate external habits by allowing consumption services to depend on past aggregate consumption of the household's income group. We find that internal habit formation plays the dominant role, whereas external habit formation has a significant but small effect on household consumption patterns. 
Our next robustness check addresses the effect of aggregate shocks in the expectation errors on the baseline estimates. As Chamberlain (1984) pointed out, the time average of the expectations errors converges to zero as time, not the number of households, increases unboundedly. We address this issue by examining whether 13 time periods is sufficiently long to expect the induced bias to be small. The Monte Carlo exercise presented in Appendix C suggests it is. This finding is also consistent with Alan, Attanasio, and Browning (2009) who show the exact nonlinear GMM estimator of the consumption Euler equation performs well even with a relatively short panel with 15 time periods. To account for aggregate effects in the expectations errors, we estimate the model with time indicators, although this treatment provides only an approximate solution to accounting for aggregate shocks in the expectation errors (see Altug and Miller 1990). We find no significant differences compared to the baseline results.

Finally, Meghir and Weber (1996) suggest nonseparabilites in preferences over food and other consumption goods might explain the finding of habit formation in food consumption. Carrasco, Labeaga, and Lopez-Salido (2005) point out that Meghir and Weber's conclusion might be due to the presence of time-invariant unobserved heterogeneity that Meghir and Weber do not account for, because of the short panel used in their estimation. Our estimation method does control for time-invariant heterogeneity. Furthermore, if nonseparabilites in preferences over food and other consumption goods represent a significant misspecification in our model, this misspecification would likely be detected in the $J$-test, similarly to the specification that ignores measurement errors.

\section{INTERTEMPORAL ELASTICITY OF SUBSTITUTION AND RELATIVE RISK AVERSION}

As discussed in the introduction, habit formation generates intertemporal elasticities of substitution and relative risk aversions that are functions of past consumption. Therefore, the habitformation model has a property of generating the IES and the RRA that vary across individuals and over time. In this section, we analyze the IES and RRA that the estimates presented in previous section imply. Because heterogeneity in the IES and RRA is generated internally through the habit-forming preference specification, models with habit-forming preferences pro- 
vide an internally consistent method for analyzing the degree of heterogeneity in these economic quantities. By contrast, studies investigating heterogeneity in the IES or RRA typically adopt iso-elastic preferences and either analyze them for different economic units, or explicitly take heterogeneity into account during estimation. Attanasio and Weber (1993), Vissing-Jorgenssen (2002), and Crossley and Low (2011) undertake the former approach to analyze heterogeneity in the IES, and Alan and Browning (2010) undertake the latter approach to analyze heterogeneity in the RRA. Other approaches include survey-based analysis (Barsky, Kimball, Juster, and Shapiro 1997; Eisenhauer and Ventura 2003; Guiso and Paiella 2006) and experiment-based elicitation (Andersen, Harrison, Lau, and Rutström 2010).

The inverse IES and the RRA derived under multiplicative habit-formation preferences take the following form (see Appendix D for details):

$$
\begin{aligned}
\frac{1}{I E S_{i t}(\theta)} & =\gamma-\frac{\alpha \beta(1-\gamma) \varphi_{i t+1}\left(\frac{c_{i t+1}}{c_{i t}^{\alpha}}\right)^{1-\gamma}}{1-\alpha \beta \varphi_{i t+1}\left(\frac{c_{i t+1}}{c_{i t}^{\alpha}}\right)^{1-\gamma}}-\frac{\alpha^{2} \beta(1-\gamma) \varphi_{i t+2}\left(\frac{c_{i t+2}}{c_{i t+1}^{\alpha+1}}\right)^{1-\gamma}}{1-\alpha \beta \varphi_{i t+2}\left(\frac{c_{i t+2}}{c_{i t+1}^{\alpha}}\right)^{1-\gamma}} \\
\operatorname{RRA}_{i t}(\theta) & =\frac{\gamma-(1+\alpha(1-\gamma)) \alpha \beta \varphi_{i t+1}\left(\frac{c_{i t+1}}{c_{i t}^{\alpha}}\right)^{1-\gamma}}{1-\alpha \beta \varphi_{i t+1}\left(\frac{c_{i t+1}}{c_{i t}^{\alpha}}\right)^{1-\gamma}}
\end{aligned}
$$

For the IES and RRA to be defined, the denominators in equations (8.1) and (8.2) must not equal to zero. A sufficient condition for this restriction is that $M U_{i t}$, as defined in equation (2.3), is strictly positive for $t=2, \cdots, T-1$, in which case $\alpha \beta \varphi_{i t+1}\left(c_{i t+1} / c_{i t}^{\alpha}\right)^{1-\gamma}<1$ for $t=2, \cdots, T-1$. We maintain this condition for the rest of our analysis.

Three important observations about the IES and RRA can be made by examining equations (8.1) and (8.2). First, holding the utility curvature constant, the inverse IES and the RRA are higher for habit-forming consumers than for non-habit-forming consumers, as long as $\gamma>1$. Second, the model with habit formation implies heterogenous IES and RRA. Third, the habitformation model breaks the tight inverse relationship between the IES and the RRA implied by the iso-elastic preference specification. Therefore, the habit-formation model can explain varying IES and RRA across groups of individuals in ways time-separable utility models cannot.

If true consumption is observed, the IES and RRA in equations (8.1) and (8.2) can be readily computed. However, when measurement errors contaminate consumption, the IES and RRA are 
not observed. Furthermore, the conditional expectations of the inverse IES and the RRA do not conform to the transformation used in Theorem 3.2 to transform the Euler equation in terms of true consumption to a moment condition that is a function of observed consumption. This transformation is key in obtaining point identification of the preference parameters. Therefore, the expectations of the (inverse) IES and the RRA are in general not directly recoverable from equations (8.1) and (8.2). However, constructing bounds for the conditional expectation of these quantities is possible given the set of instruments.

The true inverse IES and RRA are those presented in equations (8.1) and (8.2) evaluated at the true parameter values, $\theta_{0}$. The next theorem presents bounds for the conditional expectations for the true IES and RRA that are defined as functions of observed consumption.

Theorem 8.1. Suppose Assumption 3.1 holds, $\gamma>1$, and $\mathcal{A}_{30}^{-1} \alpha_{0} \beta_{0} \varphi_{0 i t+1}\left(c_{i t+1}^{o} / c_{i t}^{o \alpha_{0}}\right)^{1-\gamma_{0}}<1$ almost surely for $t=2, \cdots, T-1$, where $\mathcal{A}_{30}$ is defined in equation (3.4). Then

$$
\begin{aligned}
& \left(\gamma_{0}-\left(1-\gamma_{0}\right) E\left[\frac{\mathcal{A}_{30}^{-1} \alpha_{0} \beta_{0} \varphi_{0 i t+1}\left(\frac{c_{i t+1}^{o}}{c_{i t}^{o \alpha_{0}}}\right)^{1-\gamma_{0}}}{1-\mathcal{A}_{30}^{-1} \alpha_{0} \beta_{0} \varphi_{0 i t+1}\left(\frac{c_{i t+1}^{o}}{c_{i t}^{o \alpha_{0}}}\right)^{1-\gamma_{0}}} \mid z_{i t}^{o}\right]-\alpha_{0}\left(1-\gamma_{0}\right) E\left[\frac{\mathcal{A}_{30}^{-1} \alpha_{0} \beta_{0} \varphi_{0 i t+2}\left(\frac{c_{i t+2}^{o}}{c_{i t+1}}\right)^{1-\gamma_{0}}}{1-\mathcal{A}_{30}^{-1} \alpha_{0} \beta_{0} \varphi_{0 i t+2}\left(\frac{c_{i t+2}^{o}}{c_{i t+1}}\right)^{1-\gamma_{0}}} \mid z_{i t}^{o}\right]\right)^{-1} \\
& \leq E\left[I E S_{i t}\left(\theta_{0}\right) \mid z_{i t}^{o}\right] \leq \\
& \left(\gamma_{0}-\left(1-\gamma_{0}\right) \frac{\mathcal{A}_{30}^{-1} \alpha_{0} \beta_{0} E\left[\varphi_{0 i t+1}\left(\frac{c_{i t+1}^{o}}{c_{i t}^{o \alpha_{0}}}\right)^{1-\gamma_{0}} \mid z_{i t}^{o}\right]}{1-\mathcal{A}_{30}^{-1} \alpha_{0} \beta_{0} E\left[\varphi_{0 i t+1}\left(\frac{c_{i t+1}^{o}}{c_{i t}^{o \alpha}}\right)^{1-\gamma_{0}} \mid z_{i t}^{o}\right]}-\alpha_{0}\left(1-\gamma_{0}\right) \frac{\mathcal{A}_{30}^{-1} \alpha_{0} \beta_{0} E\left[\varphi_{0 i t+2}\left(\frac{c_{i t+2}^{o}}{c_{i t+1}^{o \alpha_{0}}}\right)^{1-\gamma_{0}} \mid z_{i t}^{o}\right]}{1-\mathcal{A}_{30}^{-1} \alpha_{0} \beta_{0} E\left[\varphi_{0 i t+2}\left(\frac{c_{i t+2}^{o}}{c_{i t+1}}\right)^{1-\gamma_{0}} \mid z_{i t}^{o}\right]}\right)^{-1},
\end{aligned}
$$

and

$$
\frac{\gamma_{0}-\left(1+\alpha_{0}\left(1-\gamma_{0}\right)\right) \mathcal{A}_{30}^{-1} \alpha_{0} \beta_{0} E\left[\varphi_{0 i t+1}\left(\frac{c_{i t+1}^{o}}{c_{i t}^{o \alpha}}\right)^{1-\gamma_{0}} \mid z_{i t}^{o}\right]}{1-\mathcal{A}_{30}^{-1} \alpha_{0} \beta_{0} E\left[\varphi_{0 i t+1}\left(\frac{c_{i t+1}^{o}}{c_{i t}^{o \alpha}}\right)^{1-\gamma_{0}} \mid z_{i t}^{o}\right]} \leq E\left[R R A_{i t}\left(\theta_{0}\right) \mid z_{i t}^{o}\right] \leq E\left[\frac{\gamma_{0}-\left(1+\alpha_{0}\left(1-\gamma_{0}\right)\right) \mathcal{A}_{30}^{-1} \alpha_{0} \beta_{0} \varphi_{0 i t+1}\left(\frac{c_{i t+1}^{o}}{c_{i t}^{o \alpha}}\right)^{1-\gamma_{0}} \mid}{1-\mathcal{A}_{30}^{-1} \alpha_{0} \beta_{0} \varphi_{0 i t+1}\left(\frac{c_{i t+1}^{o}}{c_{i t}}\right)^{1-\gamma_{0}}} \mid z_{i t}^{o}\right] .
$$

Proof. See Appendix D.

The condition $\mathcal{A}_{30}^{-1} \alpha_{0} \beta_{0} \varphi_{0 i t+1}\left(c_{i t+1}^{o} / c_{i t}^{o \alpha_{0}}\right)^{1-\gamma_{0}}<1$ is analogous to the denominator restriction for equations (8.1) and (8.2). Provided the measurement error term, $\mathcal{A}_{30}$, is at least one, this restriction rules out violations due to severe measurement errors in observed consumption. In 
our simulation exercise, this condition holds for $93.5 \%$ of the observations for which the IES and RRA are defined. The bounds on the IES and the RRA presented in Theorem 8.1 are typically not sharp. To understand why, consider the inverse IES in equation (8.1). The proof of the bounds on the IES exploits the convexity of the inverse IES in the terms $\alpha_{0} \beta_{0} \varphi_{0 i s+1}\left(c_{i s+1} / c_{i s}^{\alpha_{0}}\right)^{1-\gamma_{0}}$ for $s=t, t+1$. The inverse IES is strictly convex in these terms, and as a result, the inequalities in equation (8.3) are indeed strict. The bounds for the RRA are not sharp for the same reason. However, as we show later in this section, these bounds are informative, at least in terms of investigating the level of biasedness in the IES and RRA induced by assuming the distribution of the measurement errors is log-normal.

We use the results in Theorem 8.1 to construct $95 \%$ confidence intervals for the bounds on the unconditional expectations of the IES and RRA. To further investigate the existence and significance of heterogeneity in the IES and the RRA, we also construct $95 \%$ confidence intervals for the bounds on the conditional expectations of the IES and RRA, conditioned on eight discrete categories of households. The method used to compute the confidence regions is developed in Chernozhukov, Hong, and Tamer (2007). Other recent papers concerning estimation of confidence regions for parameter sets include Romano and Shaikh (2008, 2010), Khan and Tamer (2009), Andrews and Guggenberger (2009), Andrews and Barwick (2012), Chernozhukov, Lee, and Rosen (2013), and Andrews and Shi (2013). The approach implemented in this section is similar to Example 1 of Chernozhukov, Hong, and Tamer (2007), except that in our case, the estimates of the bounds depend on the nuisance parameters $\hat{\theta}$. For self-containment, we outline the details of the computation. In what follows, we outline the construction of the confidence intervals for $E\left[I E S_{i t}\left(\theta_{0}\right) \mid z_{i t}^{o}\right]$. The confidence intervals for $E\left[R R A_{i t}\left(\theta_{0}\right) \mid z_{i t}^{o}\right]$ are constructed analogously.

Let $\bar{z}$ denote a discrete category of households. Let $E\left[\operatorname{IES} S_{i t}\left(\theta_{0}\right) \mid \bar{z}\right]_{l}$ and $E\left[\operatorname{IES} S_{i t}\left(\theta_{0}\right) \mid \bar{z}\right]_{u}$ denote the lower and upper bound on $E\left[\operatorname{IES} S_{i t}\left(\theta_{0}\right) \mid \bar{z}\right]$ defined in equation (8.3). Let $E_{n}\left[\operatorname{IE} S_{i t}(\theta) \mid \bar{z}\right]_{l}$ and $E_{n}\left[\operatorname{IES}_{i t}(\theta) \mid \bar{z}\right]_{u}$ be $E\left[\operatorname{IES} S_{i t}\left(\theta_{0}\right) \mid \bar{z}\right]_{l}$ and $E\left[\operatorname{IE} S_{i t}\left(\theta_{0}\right) \mid \bar{z}\right]_{u}$ with $\theta_{0}$ replaced with $\theta$ and the population expectations replaced with their sample analogs. The identified interval for $E\left[\operatorname{IE} S_{i t}\left(\theta_{0}\right) \mid \bar{z}\right]$ is $C\left(\theta_{0}\right)=\left[E\left[I E S_{i t}\left(\theta_{0}\right) \mid \bar{z}\right]_{l}, E\left[I E S_{i t}\left(\theta_{0}\right) \mid \bar{z}\right]_{u}\right]$. Define

$$
C_{n}(c ; \hat{\theta})=\left[E_{n}\left[I E S_{i t}(\hat{\theta}) \mid \bar{z}\right]_{l}-\sqrt{c / n}, E_{n}\left[\operatorname{IES} S_{i t}(\hat{\theta}) \mid \bar{z}\right]_{u}+\sqrt{c / n}\right]
$$


where $c \geq 0$. Under the conditions of Theorem 5.2, and because $E\left[I E S_{i t}(\theta) \mid \bar{z}\right]_{l}$ and $E\left[I E S_{i t}(\theta) \mid \bar{z}\right]_{u}$ are bounded and continuously differentiable in $\theta$ over $\Theta$, it can be shown that $C_{n}(0 ; \hat{\theta}) \stackrel{p}{\rightarrow} C\left(\theta_{0}\right)$ and

$$
\sqrt{n}\left[\begin{array}{l}
E_{n}\left[\operatorname{IES} S_{i t}(\hat{\boldsymbol{\theta}}) \mid \bar{z}\right]_{l}-E\left[\operatorname{IES}_{i t}\left(\theta_{0}\right) \mid \bar{z}\right]_{l} \\
E_{n}\left[\operatorname{IES} S_{i t}(\hat{\boldsymbol{\theta}}) \mid \bar{z}\right]_{u}-E\left[\operatorname{IES} S_{i t}\left(\theta_{0}\right) \mid \bar{z}\right]_{u}
\end{array}\right] \stackrel{d}{\longrightarrow}\left[\begin{array}{l}
W_{l}\left(\theta_{0}\right) \\
W_{u}\left(\theta_{0}\right)
\end{array}\right]=N(0, \Omega)
$$

Let $\mathcal{C}_{n}(\hat{\boldsymbol{\theta}})=\max \left[n\left(E_{n}\left[\operatorname{IES} S_{i t}(\hat{\boldsymbol{\theta}}) \mid \bar{z}\right]_{l}-E\left[\operatorname{IES} S_{i t} \mid \bar{z}\right]\right)_{+}^{2}+n\left(E_{n}\left[\operatorname{IES} S_{i t}(\hat{\boldsymbol{\theta}}) \mid \bar{z}\right]_{u}-E\left[\operatorname{IES} S_{i t} \mid \bar{z}\right]\right)_{-}^{2}\right]$ in $E\left[\operatorname{IES} S_{i t} \mid \bar{z}\right]$ over $C\left(\theta_{0}\right)$, and $\mathcal{C}\left(\theta_{0}\right)=\max \left[\left(W_{l}\left(\theta_{0}\right)\right)_{+}^{2},\left(W_{u}\left(\theta_{0}\right)\right)_{-}^{2}\right]$, where $(x)_{+}:=\max [x, 0]$ and $(x)_{-}:=\max [-x, 0]$. Then, equation (8.6) implies $\mathcal{C}_{n}(\hat{\theta}) \stackrel{d}{\rightarrow} \mathcal{C}\left(\theta_{0}\right)$. An estimator of the 0.95 quantile is $\hat{c}=\inf \{c \geq 0$ : $\left.P\left\{\mathcal{C}_{n}(\hat{\theta}) \leq c\right\} \geq 0.95\right\}$, in which case, $C_{n}(\hat{c}, \hat{\theta})$ is our estimator of the $95 \%$ confidence interval for the conditional expectation of the IES. Chernozhukov, Hong, and Tamer (2007) suggest $\hat{c}$ can be estimated by subsampling. Accordingly, we estimate $\hat{c}$ using $B_{n}=100$ draws of subsamples of size $n^{*}=972$. For each draw $i \in\left\{1, \cdots, B_{n}\right\}$, we re-estimate $\theta_{0}$, denoted by $\theta_{i}^{*}$, and use these parameter estimates to compute $C_{n^{*}}\left(\theta_{i}^{*}\right)$. The estimate, $\hat{c}$, is then computed as the 0.95 quantile of the distribution of $\left\{C_{n^{*}}\left(\theta_{i}^{*}\right), i=1, \cdots, B_{n}\right\}$. The asymptotic properties of the confidence region in Chernozhukov, Hong, and Tamer (2007) are derived under different conditions from those required in our case, because of, for example, the sampling error from our first-stage estimator for $\theta_{0}$. We analyze the performance of the proposed estimator by Monte Carlo methods. The details of, and results from the Monte Carlo exercise are presented in Appendix C.

The values of the IES under habit-forming preferences implied by the estimated bounds reported in Table 2 are substantially lower than the values of the IES reported for time-separable utility specifications (e.g., Attanasio and Weber 1993, 1995; Vissing-Jorgensen 2002). Our results are also consistent with the findings in Naik and Moore (1996), who in the habit-formation framework, find values of the IES slightly larger than our values but lower than those reported in Attanasio and Weber (1993, 1995) and Vissing-Jorgensen (2002). Our results indicate the IES is substantially less than one and quantitatively close to the small values of IES found in Hall (1988) and more recently in Pakoš (2011). Relative to the values reported in the surveybased literature, our bounds on the IES are considerably more narrow. Indeed, Barsky, Kimball, Juster, and Shapiro (1997) report a lower bound of 0.007 , compared to ours of 0.062 for the unconditional mean of the IES estimated under the baseline specification with non-parametric 
Table 2: $95 \%$ confidence intervals for the IES and RRA

\begin{tabular}{lcc} 
& \multicolumn{2}{c}{ Nonparametric ME } \\
& IES & RRA \\
Unconditional mean & {$[0.062,0.109]$} & {$[9.373,15.503]$} \\
High school graduate & {$[0.060,0.107]$} & {$[9.558,15.905]$} \\
College graduate & {$[0.061,0.110]$} & {$[9.052,15.228]$} \\
Age $\leq 40$ years & {$[0.063,0.110]$} & {$[9.297,15.135]$} \\
Age $>40$ years & {$[0.060,0.109]$} & {$[9.449,15.873]$} \\
Lagged income $\leq \$ 31 \mathrm{~K}$ & {$[0.062,0.110]$} & {$[9.315,15.474]$} \\
Lagged income $>\$ 31 \mathrm{~K}$ & {$[0.062,0.108]$} & {$[9.432,15.534]$} \\
Family size $\leq 3$ & {$[0.061,0.110]$} & {$[9.143,15.368]$} \\
Family size $>3$ & {$[0.062,0.109]$} & {$[9.463,15.555]$} \\
& & \\
& Log-normal ME \\
Unconditional mean & {$[0.108,0.153]$} & {$[6.624,9.049]$} \\
High school graduate & {$[0.108,0.153]$} & {$[6.611,9.058]$} \\
College graduate & {$[0.104,0.152]$} & {$[6.709,9.405]$} \\
Age $<=40$ years & {$[0.109,0.154]$} & {$[6.631,9.004]$} \\
Age $>40$ years & {$[0.107,0.153]$} & {$[6.618,9.095]$} \\
Lagged income $\leq \$ 31 \mathrm{~K}$ & {$[0.108,0.153]$} & {$[6.629,9.086]$} \\
Lagged income $>\$ 31 \mathrm{~K}$ & {$[0.108,0.154]$} & {$[6.619,9.012]$} \\
Family size $\leq 3$ & {$[0.104,0.151]$} & {$[6.829,9.576]$} \\
Family size $>3$ & {$[0.110,0.155]$} & {$[6.538,8.820]$} \\
& & \\
\hline
\end{tabular}

measurement errors, and an upper bound of 0.36 , compared to ours of 0.11 .

Similarly, the estimated bounds for the RRA reported in Table 2 are more narrow relative to the range of values of the RRA obtained in the literature. Values of the RRA between 2 and 16 are reported in survey-based studies (e.g., Barsky, Kimball, Juster, and Shapiro 1997; Eisenhauer and Ventura 2003; Guiso and Paiella 2006), and between 1 and 15 for the empirical consumption study of Alan and Browning (2010), which for the greatest part accommodate the bounds we find. Yet, our values for the unconditional mean of the RRA under the baseline specification in the range $[9.4,15.5]$ are clustered at the upper end of the range reported in the literature. According to the overview of the literature on consumption-based estimates of the RRA in Alan and Browning (2010), usually the estimates of the RRA range between 1 and 3 and are typically obtained using time-separable utility specifications. Our findings on the larger values of the RRA 
are, therefore, consistent with the larger RRA implied by the habit-formation preferences.

By inspecting the bounds under the log-normal distribution of the measurement errors, Table 2 conveys another important result. Our bounds suggest the log-normality assumption, so often imposed on the distribution of the measurement errors in consumption, may be far from ideal. Although our estimation results for nonparametric and log-normal measurement-error specifications, reported in columns (1) and (2) of Table 1, largely agree on the magnitude of the estimated parameters, the implied bounds for the IES and the RRA in Table 2 do not. The confidence intervals for RRA across the two model specifications intersect for only one group (households with head having a college degree) and they only narrowly overlap for the IES. This finding suggests the log-normality assumption on measurement errors in observed consumption should be used with caution.

Table 2 reports $95 \%$ confidence intervals for the conditional expectations of the IES and RRA, conditioned on eight discrete categories of households, two groups for education, age, income, and family size. We focus on the confidence intervals of our baseline model of Table 2, that is, results with nonparametric measurement errors. The group-specific confidence intervals overlap in all cases for both the IES and RRA, indicating our confidence intervals are not so informative for investigating heterogeneity in the IES and RRA.

\section{CONCLUSION}

Studies have adopted habit formation in preferences to explain a wide variety of macroeconomic phenomena. However, at the level of micro data, evidence of habit formation in consumption is mixed. Previous related micro studies impose arguably strong assumptions to obtain an estimating equation, and misspecifications due to these assumptions are likely to result in significant biases in the estimates. Our simulation exercise supports this intuition. The simulation exercise also confirms that our new exact nonlinear GMM estimator for estimation of the intertemporal consumption choice when consumption is habit-based, performs well in recovering the preference parameters, even when measurement errors with an unknown distribution contaminate observed consumption. Our results strongly suggest habit formation is an important determinant of food-consumption patterns. This evidence is robust to various alternative specifications, namely, external habit formation in preferences, aggregate shocks in expectations errors, and nonsepara- 
bility in preferences over food and other consumption goods.

Under the studied habit-formation specification, we derive the intertemporal elasticity of substitution and relative risk aversion to investigate the magnitudes and individual variations in these key economic quantities. However, the derived IES and RRA can only be computed when measurement errors in the data are not an issue. If measurement errors contaminate consumption, the IES and RRA under internal habit formation cannot be point identified. To facilitate the inference, we develop bounds on the conditional expectations of the IES and RRA and compute confidence intervals for these bounds. Our findings are consistent with the smaller IES and larger RRA generated by the habit-formation framework. We also find our confidence intervals are more narrow relative to the findings in empirical consumption models and survey-based literature.

The model presented in this paper has extensions that future work can pursue. One such consideration is to allow for richer model specifications of internal habits. The current model assumes internal habit is a function of only the previous period's consumption. The model and estimation method can be extended to include additional lags, but at the cost of a smaller number of time periods to recover the preference parameter. Another potentially fruitful direction for future work is to estimate the model using better-quality consumption data taken, for example, from administrative sources, where the issue of measurement errors is eliminated, with the possible extension to consumption goods and services other than food consumption. One would then be able to investigate the degree of heterogeneity in the IES and RRA across groups of consumers and across different categories of consumption.

Nonetheless, this paper provides new evidence in favor of micro-level intertemporal nonseparabilities in preferences over consumption services. We present a novel approach to estimating Euler equations implied from habit-forming preferences, in which we allow for the existence of measurement errors without imposing parametric specifications on their distribution. We also propose a novel approach to analyzing the IES and RRA. Our findings warrant further analysis because of their implications for idiosyncratic consumption and savings responses to various economic policy interventions. 


\section{ACKNOWLEDGEMENTS}

We thank the editor, the associate editor of this journal, and two anonymous referees for their comments, which helped us improve the paper. The authors are grateful to David DeJong, Shakeeb Khan, and Jean-François Richard for discussions and insightful comments. We also thank participants at the conferences on Panel Data (Bonn, Germany), MEA (Chicago, IL), SEA (San Antonio, TX), and seminars at the Federal Reserve Bank of St. Louis.

\section{APPENDIX A: PROOF OF THEOREM 3.2}

Proof. To obtain an expression in terms of observed consumption, we consider equation (3.2) piece by piece and express observed consumption in terms of true consumption and measurement errors, as stated above. We start with the first term:

$$
\begin{aligned}
& E\left[\beta\left(1+r_{i t+1}\right) \frac{\varphi_{i t+1}}{c_{i t+1}^{o}}\left(\frac{c_{i t+1}^{o}}{c_{i t}^{o \alpha}}\right)^{1-\gamma} \mid z_{i t}^{o}\right]= \\
& E\left[\beta\left(1+r_{i t+1}\right) \frac{\varphi_{i t+1}}{c_{i t+1}}\left(\frac{c_{i t+1}}{c_{i t}^{\alpha}}\right)^{1-\gamma} \frac{1}{v_{i t+1}}\left(\frac{v_{i t+1}}{v_{i t}^{\alpha}}\right)^{1-\gamma} \mid z_{i t}^{o}\right]= \\
& E\left[\beta\left(1+r_{i t+1}\right) \frac{\varphi_{i t+1}}{c_{i t+1}}\left(\frac{c_{i t+1}}{c_{i t}^{\alpha}}\right)^{1-\gamma} \mid z_{i t}^{o}\right] E\left[\frac{1}{v_{i t+1}}\left(\frac{v_{i t+1}}{v_{i t}^{\alpha}}\right)^{1-\gamma} \mid z_{i t}^{o}\right]= \\
& E\left[\beta\left(1+r_{i t+1}\right) \frac{\varphi_{i t+1}}{c_{i t+1}}\left(\frac{c_{i t+1}}{c_{i t}^{\alpha}}\right)^{1-\gamma} \mid z_{i t}^{o}\right] E\left[\frac{1}{v_{i t+1}}\left(\frac{v_{i t+1}}{v_{i t}^{\alpha}}\right)^{1-\gamma}\right]= \\
& E\left[\beta\left(1+r_{i t+1}\right) \frac{\varphi_{i t+1}}{c_{i t+1}}\left(\frac{c_{i t+1}}{c_{i t}^{\alpha}}\right)^{1-\gamma} \mid z_{i t}^{o}\right] \mathcal{A}_{1},
\end{aligned}
$$

where the third and fourth equalities are obtained from Assumption 3.1, and

$$
\mathcal{A}_{1}=E\left[\frac{1}{v_{i t+1}}\left(\frac{v_{i t+1}}{v_{i t}^{\alpha}}\right)^{1-\gamma}\right]
$$

Hence,

$$
E\left[\beta\left(1+r_{i t+1}\right) \frac{\varphi_{i t+1}}{c_{i t+1}}\left(\frac{c_{i t+1}}{c_{i t}^{\alpha}}\right)^{1-\gamma} \mid z_{i t}^{o}\right]=E\left[\beta \mathcal{A}_{1}^{-1}\left(1+r_{i t+1}\right) \frac{\varphi_{i t+1}}{c_{i t+1}^{o}}\left(\frac{c_{i t+1}^{o}}{c_{i t}^{o \alpha}}\right)^{1-\gamma} \mid z_{i t}^{o}\right] .
$$


The second and the third terms are transformed similarly to get

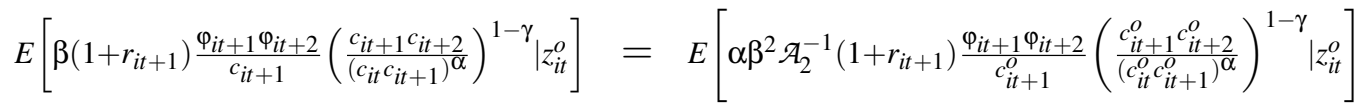

$$
\begin{aligned}
& E\left[\alpha \beta \varphi_{i t+1}\left(\frac{c_{i t+1}}{c_{i t}^{\alpha}}\right)^{1-\gamma} \mid z_{i t}^{o}\right]=E\left[\alpha \beta \mathcal{A}_{3}^{-1} \varphi_{i t+1}\left(\frac{c_{i t+1}^{o}}{c_{i t}^{o \alpha}}\right)^{1-\gamma} \mid z_{i t}^{o}\right],
\end{aligned}
$$

where

$$
\begin{aligned}
& \mathcal{A}_{2}=E\left[\frac{1}{v_{i t+1}}\left(\frac{v_{i t+1} v_{i t+2}}{\left(v_{i t} v_{i t+1}\right)^{\alpha}}\right)^{1-\gamma}\right], \quad \text { and } \\
& \mathcal{A}_{3}=E\left[\left(\frac{v_{i t+1}}{v_{i t}^{\alpha}}\right)^{1-\gamma}\right] .
\end{aligned}
$$

The moment condition (3.2) for (unobserved) true consumption is therefore transformed into a moment condition for observed consumption:

$$
E\left[\beta\left(1+r_{i t+1} \frac{\varphi_{i t+1}}{c_{i t+1}^{o}}\left(\frac{c_{i t+1}^{o}}{c_{i t}^{o \alpha}}\right)^{1-\gamma}\left(\mathcal{A}_{1}^{-1}-\alpha \beta \mathcal{A}_{2}^{-1} \varphi_{i t+2}\left(\frac{c_{i+2}^{o}}{c_{i t+1}^{o \alpha}}\right)^{1-\gamma}\right)-\left(1-\alpha \beta \mathcal{A}_{3}^{-1} \varphi_{i t+1}\left(\frac{c_{i+1}^{o}}{c_{i t}^{o \alpha}}\right)^{1-\gamma}\right) \mid z_{i t}^{o}\right]=0 .\right.
$$

\section{APPENDIX B: $\quad$ PROOF OF THEOREM 4.2}

Proof. Recall that

$$
\rho\left(x_{i t}^{o, t+2}, \theta\right)=\beta\left(1+r_{i t+1} \frac{\varphi_{i t+1}}{c_{i t+1}^{o}}\left(\frac{c_{i t+1}^{o}}{c_{i t}^{o, \alpha}}\right)^{1-\gamma}\left(\kappa_{1}-\alpha \beta \varphi_{i t+2}\left(\frac{c_{i t+2}^{o o}}{c_{i t+1}^{o, \alpha}}\right)^{1-\gamma}\right)-\left(\kappa_{2}-\alpha \beta \kappa_{3} \varphi_{i t+1}\left(\frac{c_{i t+1}^{o}}{c_{i t}^{o, \alpha}}\right)^{1-\gamma}\right) .\right.
$$

Equation (3.3) implies $E\left[\rho\left(x_{i t}^{o, t+2}, \theta_{0}\right) \mid z_{i t}^{o}\right]=0$. Suppose another set of parameters $\theta \in \Theta$ exists that satisfies $E\left[\rho\left(x_{i t}^{o, t+2}, \theta\right) \mid z_{i t}^{o}\right]=0$. Then $E\left[l\left(x_{i t}^{o, t+2}, \theta, \theta_{0}\right) \mid z_{i t}^{o}\right]=0$, where $l\left(x_{i t}^{o, t+2}, \theta, \theta_{0}\right)=$ $\rho\left(x_{i t}^{o, t+2}, \theta\right)-\rho\left(x_{i t}^{o, t+2}, \theta_{0}\right)$. This equality and Assumption 4.1.i imply

$$
l\left(x_{i t}^{o, t+2}, \theta, \theta_{0}\right)=\rho\left(x_{i t}^{o, t+2}, \theta\right)-\rho\left(x_{i t}^{o, t+2}, \theta_{0}\right)=0
$$

almost surely. For the remainder of this proof, we drop the $o$ superscript on consumption for ease of exposition. 
First, suppose $\alpha_{0}=0$. Then if $\alpha>0$, holding $\left(r_{i t+1}, \Delta w_{i t+1}, \Delta w_{i t+2}, c_{i t}, c_{i t+1}\right)$ constant, $\rho\left(x_{i t}^{o, t+2}, \theta_{0}\right)$ is constant while $\rho\left(x_{i t}^{o, t+2}, \theta\right)$ varies monotonically with $c_{i t+2}$, violating equation (B.1). Therefore, if $\alpha_{0}=0$, then $\alpha=0$. Suppose $\alpha_{0}>0$. Then if $\alpha=0$, holding $\left(r_{i t+1}, \Delta w_{i t+1}, \Delta w_{i t+2}, c_{i t}, c_{i t+1}\right)$ constant, $\rho\left(x_{i t}^{o, t+2}, \theta\right)$ is constant while $\rho\left(x_{i t}^{o, t+2}, \theta_{0}\right)$ varies monotonically with $c_{i t+2}$, violating equation (B.1). Therefore, if $\alpha_{0}>0$, then $\alpha>0$. If $\alpha=\alpha_{0}=0$, then equation (B.1) implies

$$
\kappa_{1} \beta\left(1+r_{i t+1}\right) \varphi_{i t+1} c_{i t+1}^{-\gamma}-\kappa_{2}=\kappa_{10} \beta_{0}\left(1+r_{i t+1}\right) \varphi_{0 i t+1} c_{i t+1}^{-\gamma_{0}}-\kappa_{20},
$$

almost surely, where $\varphi_{0 i t+1}=\exp \left(\delta_{0} \Delta w_{i t+1}\right)$. Differentiating equation (B.2) with respect to $r_{i t+1}$, taking logs, and gathering terms obtains

$$
\ln \left(\kappa_{1} \beta / \kappa_{10} \beta_{0}\right)+\Delta w_{i t+1}\left(\delta-\delta_{0}\right)-\left(\gamma-\gamma_{0}\right) \ln c_{i t+1}=0
$$

almost surely. By differentiating equation (B.3) with respect to $\ln c_{i t+1}$, we have $\gamma=\gamma_{0}$. This result and equation (B.3) imply

$$
\ln \left(\kappa_{1} \beta / \kappa_{10} \beta_{0}\right)+\Delta w_{i t+1}\left(\delta-\delta_{0}\right)=0,
$$

almost surely. Under Assumption 4.1.ii, and the fact that every subset of a linearly independent set is also linearly independent, equation (B.4) implies $\kappa_{1} \beta=\kappa_{10} \beta_{0}$ and $\delta=\delta_{0}$. Substituting these equalities into equation (B.2) gives $\kappa_{2}=\kappa_{20}$. Recall that $\kappa_{20}=\mathcal{A}_{20}$ and $\kappa_{10}=\mathcal{A}_{20} / \mathcal{A}_{10}$. Then, from identification of $\mathcal{A}_{20}$ and $\kappa_{10} \beta_{0}, \mathcal{A}_{10}^{-1} \beta_{0}$ is identified. If Assumption 3.3 is satisfied, then $\sigma_{0}$ is identified from the identification of $\gamma_{0}, \alpha_{0}$, and $\mathcal{A}_{20}$, along with the equality $\mathcal{A}_{20}=\exp \left\{\sigma_{0}^{2}\left(\alpha_{0}^{2}\left(1-\gamma_{0}\right)^{2}+\gamma_{0}^{2}+\left(1-\gamma_{0}\right)\left(1+\alpha_{0}\right)\right)\right\}$, which in turn implies identification of $\mathcal{A}_{10}=\exp \left\{\sigma_{0}^{2}\left(\alpha_{0}^{2}\left(1-\gamma_{0}\right)^{2}+\gamma_{0}^{2}+\alpha_{0} \gamma_{0}\left(1-\gamma_{0}\right)\right)\right\}$ and $\mathcal{A}_{30}=\exp \left\{\sigma_{0}^{2}\left(\left(1+\alpha_{0}+\alpha_{0}^{2}\right)\left(1-\gamma_{0}\right)^{2}\right)\right\}$. Finally, identification of $\mathcal{A}_{10}$ and $\mathcal{A}_{10}^{-1} \beta_{0}$ imply identification of $\beta_{0}$.

Suppose $\alpha>0$ and $\alpha_{0}>0$. Taking the derivative of equation (B.1) with respect to $c_{i t+2}$ and $c_{i t}$ then obtains

$$
\begin{aligned}
& (\alpha \beta(1-\gamma))^{2} \psi_{i t+2} c_{i t}^{-\alpha(1-\gamma)-1} c_{i t+1}^{-\gamma-\alpha(1-\gamma)} c_{i t+2}^{-\gamma} \\
& -\left(\alpha_{0} \beta_{0}\left(1-\gamma_{0}\right)\right)^{2} \psi_{0 i t+2} c_{i t}^{-\alpha_{0}\left(1-\gamma_{0}\right)-1} c_{i t+1}^{-\gamma_{0}-\alpha_{0}\left(1-\gamma_{0}\right)} c_{i t+2}^{-\gamma_{0}}=0
\end{aligned}
$$


almost surely, where $\psi_{i t}=\exp \left(\left(\Delta w_{i t+1}+\Delta w_{i t+2}\right) \delta\right)$ and $\psi_{0 i t}=\exp \left(\left(\Delta w_{i t+1}+\Delta w_{i t+2}\right) \delta_{0}\right)$. Taking logs of equation (B.5) and collecting terms obtains

$$
\begin{aligned}
& \mu+\left(\Delta w_{i t+1}+\Delta w_{i t+2}\right)\left(\delta-\delta_{0}\right)-\left[\alpha(1-\gamma)-\alpha_{0}\left(1-\gamma_{0}\right)\right] \ln c_{i t} \\
& -\left[\gamma+\alpha(1-\gamma)-\gamma_{0}-\alpha_{0}\left(1-\gamma_{0}\right)\right] \ln c_{i t+1}-\left(\gamma-\gamma_{0}\right) \ln c_{i t+2}=0
\end{aligned}
$$

almost surely, where $\mu=\ln \left(\left[\alpha \beta(1-\gamma) / \alpha_{0} \beta_{0}\left(1-\gamma_{0}\right)\right]^{2}\right)$. Differentiating equation (B.6) with respect to $\ln c_{i t+2}$ obtains $\gamma=\gamma_{0}$. Using this result and differentiating equation (B.6) with respect to $\ln c_{i t}$ obtains $\alpha=\alpha_{0}$. These two results and equation (B.6) imply

$$
\mu+\left(\Delta w_{i t+1}+\Delta w_{i t+2}\right)\left(\delta-\delta_{0}\right)=0
$$

almost surely. Equation (B.7) and Assumption 4.1.ii imply $\delta=\delta_{0}$, and $\mu=0$. From $\gamma=\gamma_{0}, \alpha=\alpha_{0}$, and $\mu=0$, we have that $\beta=\beta_{0}$. Substituting these results into equation (B.1) obtains

$$
\left(\kappa_{1}-\kappa_{10}\right) \beta_{0}\left(1+r_{i t+1}\right) \frac{\varphi_{0 i t+1}}{c_{i t+1}}\left(\frac{c_{i t+1}}{c_{i t}^{\alpha}}\right)^{1-\gamma_{0}}+\left(\kappa_{3}-\kappa_{30}\right) \alpha_{0} \beta_{0} \varphi_{0 i t+1}\left(\frac{c_{i t+1}}{c_{i t}^{\alpha_{0}}}\right)^{1-\gamma_{0}}+\left(\kappa_{20}-\kappa_{2}\right)=0
$$

almost surely. Differentiating equation (B.8) with respect to $1+r_{i t+1}$ implies $\kappa_{1}=\kappa_{10}$. Substituting this result into equation (B.8) and differentiating with respect to $c_{i t+1}$ obtain $\kappa_{3}=\kappa_{30}$, which in turn implies $\kappa_{2}=\kappa_{20}$. Identification of $\left(\mathcal{A}_{10}, \mathcal{A}_{20}, \mathcal{A}_{30}\right)$, and therefore $\theta_{0}$, is then obtained from $\left(\kappa_{10}, \kappa_{20}, \kappa_{30}\right)$. Finally, if Assumption 3.3 is satisfied, then $\sigma_{0}$ is identified from the identification of $\theta_{0}$ and the equality $\mathcal{A}_{20}=\exp \left\{\sigma_{0}^{2}\left(\alpha_{0}^{2}\left(1-\gamma_{0}\right)^{2}+\gamma_{0}^{2}+\left(1-\gamma_{0}\right)\left(1+\alpha_{0}\right)\right)\right\}$.

\section{APPENDIX C: MONTE CARLO EXPERIMENT}

In this section, we investigate the finite-sample performance of the estimator developed in section 3 , as well as the performance of the approximated log-linearized habit-formation model. We do so by conducting a Monte Carlo simulation in which the life-cycle model presented in section 2 is solved under labor income and interest rate uncertainty. The details of the solution and simulation methods are standard for the intertemporal utility optimization framework and available from the authors upon request. The structural parameter values are set as follows: $\gamma=5, \alpha=0.85, \beta=$ 
Table 3: Estimation of the Euler equation with habit formation, using simulated data

\begin{tabular}{|c|c|c|c|c|c|}
\hline Parameters & $\begin{array}{l}\text { Truth } \\
\text { (1) }\end{array}$ & $\begin{array}{l}\text { No ME } \\
\text { (2) }\end{array}$ & $\begin{array}{c}\text { Log-normal } \mathrm{ME} \\
\text { (3) }\end{array}$ & $\begin{array}{c}\text { Nonparametric ME } \\
\text { (4) }\end{array}$ & $\begin{array}{l}\text { Ignoring } \mathrm{ME} \\
\text { (5) }\end{array}$ \\
\hline$\gamma$ & 5.00 & $\begin{array}{c}4.93 \\
{[4.89]} \\
(0.33)\end{array}$ & $\begin{array}{c}5.73 \\
{[4.98]} \\
(2.65)\end{array}$ & $\begin{array}{c}5.16 \\
{[5.00]} \\
(1.03)\end{array}$ & $\begin{array}{c}13.22 \\
{[13.32]} \\
(2.03)\end{array}$ \\
\hline$\beta$ & 0.95 & $\begin{array}{c}0.95 \\
{[0.95]} \\
(0.01)\end{array}$ & $\begin{array}{c}0.94 \\
{[0.95]} \\
(0.07)\end{array}$ & $\begin{array}{c}0.95 \\
{[0.95]} \\
(0.01)\end{array}$ & $\begin{array}{c}0.74 \\
{[0.74]} \\
(0.05)\end{array}$ \\
\hline$\alpha$ & 0.85 & $\begin{array}{c}0.85 \\
{[0.85]} \\
(0.01)\end{array}$ & $\begin{array}{c}0.85 \\
{[0.85]} \\
(0.03)\end{array}$ & $\begin{array}{c}0.85 \\
{[0.85]} \\
(0.01)\end{array}$ & $\begin{array}{c}0.55 \\
{[0.55]} \\
(0.05)\end{array}$ \\
\hline$\sigma^{2}$ & 0.04 & & $\begin{array}{c}0.04 \\
{[0.03]} \\
(0.04)\end{array}$ & & \\
\hline
\end{tabular}

NOTE: In estimation, we reduce the time dimension of the artificial data panel to 13 years. The instrument set includes current and past interest rates and current income. Standard errors are in parentheses. Medians are in square brackets.

0.95. The interest-rate series is a stationary $\operatorname{AR}(1)$ process with a mean of 0.05 and autoregressive coefficient of 0.6. We solve the model for 40 periods; however, in estimation, we only use the 13 middle periods in order to match the length of the artificial panel with the one used in the empirical analysis. Additionally, due to this trimming, starting and ending effects of the artificial consumption series are not an issue. Consumption paths are simulated to obtain 100 samples of 1,700 households observed over 13 periods. Next, the simulated consumption data are contaminated by measurement errors drawn independently over households and time from a log-normal distribution with variance equal to $75 \%$ of the variance in consumption.

Table 3 presents results from the Monte Carlo investigation of the estimator developed in section 3. Column (1) gives the true values of the preference parameters that we aim to recover using the proposed estimator. Column (2) shows the estimator performs well in the absence of 
Table 4: Estimation of equation (C.1) using the simulated data

\begin{tabular}{lcccc}
\hline Parameters & \multicolumn{2}{c}{ No ME } & \multicolumn{2}{c}{ Nonparametric ME } \\
& $(1)$ & $(2)$ & $(3)$ & $(4)$ \\
& & & & \\
\hline & & & & \\
$\beta_{0}($ Constant $)$ & 0.042 & -0.005 & 0.175 & 0.094 \\
& {$[0.041]$} & {$[-0.006]$} & {$[0.175]$} & {$[0.094]$} \\
& $(0.040)$ & $(0.039)$ & $(0.047)$ & $(0.048)$ \\
$\alpha\left(\Delta \ln C_{i t-1}^{o}\right)$ & 0.170 & 0.197 & 0.106 & 0.163 \\
& {$[0.171]$} & {$[0.197]$} & {$[0.105]$} & {$[0.161]$} \\
& $(0.015)$ & $(0.015)$ & $(0.020)$ & $(0.021)$ \\
$\beta_{1}($ Age $)$ & 0.0001 & -0.0004 & -0.013 & -0.012 \\
& {$[0.0001]$} & {$[-0.0003]$} & {$[-0.013]$} & {$[-0.011]$} \\
& $(0.004)$ & $(0.004)$ & $(0.004)$ & $(0.005)$ \\
$\beta_{2}($ Age $2 / 1000)$ & -0.091 & -0.077 & 0.204 & 0.194 \\
& {$[-0.097]$} & {$[0.082]$} & {$[0.192]$} & {$[0.180]$} \\
& $(0.101)$ & $(0.099)$ & $(0.121)$ & $(0.120)$ \\
$\beta_{3}\left(\ln \left(1+r_{t}\right)\right)$ & - & 1.121 & - & 1.540 \\
& & {$[1.112]$} & & {$[1.525]$} \\
& & $(0.149)$ & & $(0.243)$
\end{tabular}

NOTE: The instrument set includes the first two lags of income growth and lagged interest rate. In columns (2) and (4), $\ln \left(1+r_{t}\right)$ is treated as endogenous. Standard errors are in parentheses.

consumption measurement errors. The results also show the estimator performs well when the distribution of measurement errors is known to be log-normal (column 3) and when the distribution of measurement errors is unknown (column 4). Column (5) shows that not accounting for measurement errors results in upward bias in $\gamma$ and downward bias in $\alpha$ and $\beta$.

With the simulated data in hand, we investigate the performance of estimation of the linear approximation models developed in Hayashi (1985), Muellbauer (1988), and Dynan (2000). The derivation of the estimator for the additive habit-formation model assumes (i) interest rates do not vary across individuals or over time, (ii) individuals live for an infinite period, and (iii) $\Delta \ln \left(C_{t}-\alpha C_{t-1}\right) \approx \Delta \ln C_{t}-\alpha \Delta \ln C_{t-1}$. We derive a comparable estimator for which the first 
two assumptions are maintained. As Muellbauer (1988) shows, the third assumption requires that consumption does not vary significantly over time. In the multiplicative habit model, this assumption and the first two assumptions imply instrumental variable estimation of

$$
\Delta \ln C_{i t}^{o}=\beta_{0}+\alpha \Delta \ln C_{i t-1}^{o}+\beta_{1} a g e_{t}+\beta_{2} a g e^{2}+\varepsilon_{t}
$$

should yield $\alpha=0.85$. The instruments for $\Delta \ln C_{i t-1}^{o}$ are the first two lags of income growth and the lagged interest rate.

Table 4 reports two sets of results from the Monte Carlo investigation of this estimation method. The first two columns are the results for the case of the absence of consumption measurement errors, and the last two are for the case when consumption is measured with errors. The results show significant downward bias in the estimate of $\alpha$ even without consumption measurement errors. These results suggest the assumptions made to obtain equation (C.1) are substantial. The bias is more severe when consumption is measured with errors.

Lastly, we perform a Monte Carlo exercise to investigate the accuracy of the estimated confidence interval for the mean IES, presented in equation (8.5), and the analogously estimated confidence interval for the mean RRA. Specifically, we use the simulated consumption data without measurement errors to compute the simulated mean IES and RRA. The simulation exercise obtains the mean IES of 0.072 and the mean RRA of 13.05. Next, we use the simulated data samples of consumption contaminated with measurement errors to compute their $95 \%$ confidence intervals by implementing the bootstrap approach presented in section 8 . We find the simulated mean IES falls within the estimated confidence intervals in $96 \%$ of the replications, whereas the simulated mean RRA falls within the estimated confidence intervals in $92 \%$ of the replications.

\section{APPENDIX D: $\quad$ PROOF OF THEOREM 8.1}

Proof. The individual-specific intertemporal elasticity of substitution can be found from:

$$
\frac{1}{I E S_{i t}}=\left|\frac{\partial \ln \frac{M U_{i t}}{M U_{i t+1}}}{\partial \ln \frac{C_{i t+1}}{C_{i t}}}\right|
$$


where

$$
\begin{aligned}
\frac{M U_{i t}}{M U_{i t+1}} & =\frac{\frac{\phi_{i t}}{C_{i t}}\left(\frac{C_{i t}}{C_{i t-1}^{i}}\right)^{1-\gamma}-\alpha \beta \frac{\phi_{i t+1}}{C_{i t}}\left(\frac{C_{i t+1}}{C_{i t}^{\alpha}}\right)^{1-\gamma}}{\frac{\phi_{i t+1}}{C_{i t+1}}\left(\frac{C_{i t+1}}{C_{i t}^{\alpha}}\right)^{1-\gamma}-\alpha \beta \frac{\phi_{i t+2}}{C_{i t+1}}\left(\frac{C_{i t+2}}{C_{i t+1}^{\alpha}}\right)^{1-\gamma}} \\
& =\frac{\left(1-\alpha \beta \varphi_{i t+1}\left(\frac{c_{i t+1}}{c_{i t}^{\alpha}}\right)^{1-\gamma}\right)}{\frac{\varphi_{i t+1}}{c_{i t+1}}\left(\frac{c_{i t+1}}{c_{i t}^{\alpha}}\right)^{1-\gamma}\left(1-\alpha \beta \varphi_{i t+2}\left(\frac{c_{i t+2}}{c_{i t+1}^{\alpha}}\right)^{1-\gamma}\right)} .
\end{aligned}
$$

Taking logs of (D.2) and partial derivatives with respect to $\ln c_{i t+1}=\ln \left(C_{i t+1} / C_{i t}\right)$, we obtain

$$
\frac{1}{I E S_{i t}(\theta)}=\gamma-\frac{\alpha \beta(1-\gamma) \varphi_{i t+1}\left(\frac{c_{i t+1}}{c_{i t}^{\alpha}}\right)^{1-\gamma}}{1-\alpha \beta \varphi_{i t+1}\left(\frac{c_{i t+1}}{c_{i t}^{\alpha}}\right)^{1-\gamma}}-\frac{\alpha^{2} \beta(1-\gamma) \varphi_{i t+2}\left(\frac{c_{i t+2}}{c_{i t+1}^{\alpha}}\right)^{1-\gamma}}{1-\alpha \beta \varphi_{i t+2}\left(\frac{c_{i t+2}}{c_{i t+1}}\right)^{1-\gamma}} .
$$

Recall that under Assumption 3.1,

$$
E\left[\alpha \beta \varphi_{i t+1}\left(\frac{c_{i t+1}}{c_{i t}^{\alpha}}\right)^{1-\gamma} \mid z_{i t}^{o}\right]=E\left[\alpha \beta \mathcal{A}_{3}^{-1} \varphi_{i t+1}\left(\frac{c_{i t+1}^{o}}{c_{i t}^{o \alpha}}\right)^{1-\gamma} \mid z_{i t}^{o}\right] .
$$

Note also that

$$
\begin{aligned}
M U_{i t}\left(\theta_{0}\right) & =\frac{\phi_{0 i t}}{C_{i t}}\left(\frac{C_{i t}}{C_{i t-1}^{\alpha_{0}}}\right)^{1-\gamma_{0}}-\alpha_{0} \beta_{0} \frac{\phi_{0 i t+1}}{C_{i t}}\left(\frac{C_{i t+1}}{C_{i t}^{\alpha_{0}}}\right)^{1-\gamma_{0}} \\
& =\frac{\phi_{0 i t}}{C_{i t}}\left(\frac{C_{i t}}{C_{i t-1}^{\alpha_{0}}}\right)^{1-\gamma_{0}}\left(1-\alpha_{0} \beta_{0} \varphi_{0 i t+1}\left(\frac{c_{i t+1}}{c_{i t}^{\alpha_{0}}}\right)^{1-\gamma_{0}}\right) .
\end{aligned}
$$

Because $\alpha_{0} \beta_{0} \varphi_{0 i t+1}\left(c_{i t+1} / c_{i t}^{\alpha_{0}}\right)^{1-\gamma_{0}}<1$, the inverse IES is convex in $\alpha_{0} \beta_{0} \varphi_{0 i t+1}\left(c_{i t+1} / c_{i t}^{\alpha_{0}}\right)^{1-\gamma_{0}}$ and $\alpha_{0} \beta_{0} \varphi_{0 i t+2}\left(c_{i t+2} / c_{i t+1}^{\alpha_{0}}\right)^{1-\gamma_{0}}$. Therefore, Jensen's inequality, along with equations (D.3) and 
(D.4), obtain

$$
\begin{aligned}
& E\left[\frac{1}{I E S_{i t}\left(\theta_{0}\right)} \mid z_{i t}^{o}\right] \geq \gamma_{0}-\left(1-\gamma_{0}\right) \frac{\alpha_{0} \beta_{0} E\left[\varphi_{0 i t+1}\left(\frac{c_{i t+1}}{c_{i t}}\right)^{1-\gamma_{0}} \mid z_{i t}^{o}\right]}{1-\alpha_{0} \beta_{0} E\left[\varphi_{0 i t+1}\left(\frac{c_{i t+1}}{c_{i t}^{\alpha_{0}}}\right)^{1-\gamma_{0}} \mid z_{i t}^{o}\right]}-\alpha_{0}\left(1-\gamma_{0}\right) \frac{\alpha_{0} \beta_{0} E\left[\left.\varphi_{0 i t+2}\left(\frac{c_{i t+2}}{c_{0}}\right)^{1-\gamma_{0}}\right|_{z_{i t+1}^{o}}\right]}{1-\alpha_{0} \beta_{0} E\left[\left.\varphi_{0 i t+2}\left(\frac{c_{i t+2}}{c_{0}}\right)^{1-\gamma_{0}}\right|_{z i t+1} ^{o}\right]} \\
& =\gamma_{0}-\left(1-\gamma_{0}\right) \frac{\mathcal{A}_{30}^{-1} \alpha_{0} \beta_{0} E\left[\varphi_{0 i t+1}\left(\frac{c_{i t+1}^{o}}{c_{i t}^{\circ \alpha_{0}}}\right)^{1-\gamma_{0}} \mid z_{i t}^{o}\right]}{1-\mathcal{A}_{30}^{-1} \alpha_{0} \beta_{0} E\left[\varphi_{0 i t+1}\left(\frac{c_{i t+1}^{o}}{c_{i t}^{o \alpha_{0}}}\right)^{1-\gamma_{0}} \mid z_{i t}^{o}\right]}-\alpha_{0}\left(1-\gamma_{0}\right) \frac{\mathcal{A}_{30}^{-1} \alpha_{0} \beta_{0} E\left[\varphi_{0 i t+2}\left(\frac{c_{i t+2}^{o}}{c_{i t+1}^{o 0_{0}}}\right)^{1-\gamma_{0}} \mid z_{i t}^{o}\right]}{1-\mathcal{A}_{30}^{-1} \alpha_{0} \beta_{0} E\left[\varphi_{0 i t+2}\left(\frac{c_{i t+2}^{o}}{c_{i t+1} \alpha_{0}}\right)^{1-\gamma_{0}} \mid z_{i t}^{o}\right]} .
\end{aligned}
$$

Also, because the IES is concave in $\alpha_{0} \beta_{0} \varphi_{0 i t+1}\left(c_{i t+1} / c_{i t}^{\alpha_{0}}\right)^{1-\gamma_{0}}$ and $\alpha_{0} \beta_{0} \varphi_{0 i t+2}\left(c_{i t+2} / c_{i t+1}^{\alpha_{0}}\right)^{1-\gamma_{0}}$, Jensen's inequality, along with equations (D.3) and (D.4), obtains

$$
E\left[I E S_{i t}\left(\theta_{0}\right) \mid z_{i t}^{o}\right] \leq\left(\gamma_{0}-\left(1-\gamma_{0}\right) \frac{\mathcal{A}_{30}^{-1} \alpha_{0} \beta_{0} E\left[\varphi_{0 i t+1}\left(\frac{c_{i t+1}^{o}}{c_{i t}^{o \alpha_{0}}}\right)^{1-\gamma_{0}} \mid z_{i t}^{o}\right]}{1-\mathcal{A}_{30}^{-1} \alpha_{0} \beta_{0} E\left[\varphi_{0 i t+1}\left(\frac{c_{i t+1}^{o}}{\left.c_{i t}^{o \alpha}\right)_{0}}\right)^{1-\gamma_{0}} \mid z_{i t}^{o}\right]}-\alpha_{0}\left(1-\gamma_{0}\right) \frac{\mathcal{A}_{30}^{-1} \alpha_{0} \beta_{0} E\left[\varphi_{0 i t+2}\left(\frac{c_{i t+2}^{o}}{c_{i t+1}^{o}}\right)^{1-\gamma_{0}} \mid z_{i t}^{o}\right]}{1-\mathcal{A}_{30}^{-1} \alpha_{0} \beta_{0} E\left[\varphi_{0 i t+2}\left(\frac{c_{i t+2}^{o}}{c_{i t+1}^{o \alpha_{0}}}\right)^{1-\gamma_{0}} \mid z_{i t}^{o}\right]}\right)^{-1} .
$$

To derive an upper bound for the inverse IES, note that equation (D.3) has the following representation:

$$
\begin{aligned}
\frac{1}{I E S_{i t}\left(\theta_{0}\right)}= & \gamma_{0}-\alpha_{0} \beta_{0}\left(1-\gamma_{0}\right) \varphi_{0 i t+1}\left(\frac{c_{i t+1}}{c_{i t}^{\alpha_{0}}}\right)^{1-\gamma_{0}} \sum_{j=0}^{\infty}\left(\alpha_{0} \beta_{0} \varphi_{0 i t+1}\left(\frac{c_{i t+1}}{c_{i t}^{\alpha_{0}}}\right)^{1-\gamma_{0}}\right)^{j} \\
& -\alpha_{0}^{2} \beta_{0}\left(1-\gamma_{0}\right) \varphi_{0 i t+2}\left(\frac{c_{i t+2}}{c_{i t+1}^{\alpha_{0}}}\right)^{1-\gamma_{0}} \sum_{j=0}^{\infty}\left(\alpha_{0} \beta_{0} \varphi_{0 i t+2}\left(\frac{c_{i t+2}}{c_{i t+1}^{\alpha_{0}}}\right)^{1-\gamma_{0}}\right)^{j} \\
= & \gamma_{0}-\left(1-\gamma_{0}\right) \sum_{j=1}^{\infty}\left(\alpha_{0} \beta_{0} \varphi_{0 i t+1}\left(\frac{c_{i t+1}}{c_{i t}^{\alpha_{0}}}\right)^{1-\gamma_{0}}\right)^{j}-\alpha_{0}\left(1-\gamma_{0}\right) \sum_{j=1}^{\infty}\left(\alpha_{0} \beta_{0} \varphi_{0 i t+2}\left(\frac{c_{i t+2}}{c_{i t+1}^{\alpha_{0}}}\right)^{1-\gamma_{0}}\right)^{j},
\end{aligned}
$$

which is a valid representation because the assumption of positive marginal utility implies each term in the infinite sum is between 0 and 1 . For the same reason, the dominated convergence theorem applies and we find

$$
\begin{aligned}
E\left[\frac{1}{I E S_{i t}\left(\theta_{0}\right)} \mid z_{i t}^{o}\right]= & \gamma_{0}-\left(1-\gamma_{0}\right) \sum_{j=1}^{\infty} E\left[\left(\alpha_{0} \beta_{0} \varphi_{0 i t+1}\left(\frac{c_{i t+1}}{c_{i t}^{\alpha}}\right)^{1-\gamma_{0}}\right)^{j} \mid z_{i t}^{o}\right] \\
& -\alpha_{0}\left(1-\gamma_{0}\right) \sum_{j=1}^{\infty} E\left[\left(\alpha_{0} \beta_{0} \varphi_{0 i t+2}\left(\frac{c_{i t+2}}{c_{i t+1}^{\alpha_{0}}}\right)^{1-\gamma_{0}}\right)^{j} \mid z_{i t}^{o}\right] .
\end{aligned}
$$


Next, for each $j$, we have

$$
\begin{aligned}
E\left[\left(\alpha_{0} \beta_{0} \varphi_{0 i t+1}\left(\frac{c_{i t+1}^{o}}{c_{i t}^{o \alpha_{0}}}\right)^{1-\gamma_{0}}\right)^{j} \mid z_{i t}^{o}\right] & =E\left[\left(\alpha_{0} \beta_{0} \varphi_{0 i t+1}\left(\frac{c_{i t+1}}{c_{i t}^{\alpha_{0}}}\right)^{1-\gamma_{0}}\right)^{j}\left(\left(\frac{v_{i t+1}}{v_{i t}^{\alpha_{0}}}\right)^{1-\gamma_{0}}\right)^{j} \mid z_{i t}^{o}\right] \\
& =E\left[\left(\alpha_{0} \beta_{0} \varphi_{0 i t+1}\left(\frac{c_{i t+1}}{c_{i t}^{\alpha_{0}}}\right)^{1-\gamma_{0}}\right)^{j} \mid z_{i t}^{o}\right] E\left[\left(\left(\frac{v_{i t+1}}{v_{i t}}\right)^{1-\gamma_{0}}\right)^{j} \mid z_{i t}^{o}\right]
\end{aligned}
$$

Because $j \geq 1$, Jensen's inequality implies

$$
E\left[\left(\left(\frac{v_{i t+1}}{v_{i t}^{\alpha_{0}}}\right)^{1-\gamma_{0}}\right)^{j} \mid z_{i t}^{o}\right] \geq\left(E\left[\left(\frac{v_{i t+1}}{v_{i t}^{\alpha_{0}}}\right)^{1-\gamma_{0}} \mid z_{i t}^{o}\right]\right)^{j}=\mathcal{A}_{30}^{j} .
$$

Therefore, equations (D.5) and (D.6) obtain

$$
E\left[\left(\mathcal{A}_{30}^{-1} \alpha_{0} \beta_{0} \varphi_{0 i t+1}\left(\frac{c_{i t+1}^{o}}{c_{i t}^{o \alpha_{0}}}\right)^{1-\gamma_{0}}\right)^{j} \mid z_{i t}^{o}\right] \geq E\left[\left(\alpha_{0} \beta_{0} \varphi_{0 i t+1}\left(\frac{c_{i t+1}}{c_{i t}{ }^{\alpha}}\right)^{1-\gamma_{0}}\right)^{j} \mid z_{i t}^{o}\right] .
$$

Substituting equation (D.7) into equation (D.5) obtains

$$
\begin{aligned}
E\left[\frac{1}{I E S_{i t}\left(\theta_{0}\right)} \mid z_{i t}^{o}\right] \leq \gamma_{0}-\left(1-\gamma_{0}\right) \sum_{j=1}^{\infty} E\left[\left(\mathcal{A}_{30}^{-1} \alpha_{0} \beta_{0} \varphi_{0 i t+1}\left(\frac{c_{i t+1}^{o}}{c_{i t}^{o \alpha_{0}}}\right)^{1-\gamma_{0}}\right)^{j} \mid z_{i t}^{o}\right] \\
-\alpha_{0}\left(1-\gamma_{0}\right) \sum_{j=1}^{\infty} E\left[\left(\mathcal{A}_{30}^{-1} \alpha_{0} \beta_{0} \varphi_{0 i t+2}\left(\frac{c_{i t+2}^{o}}{c_{i t+1}^{o \alpha_{0}}}\right)^{1-\gamma_{0}}\right)^{j} \mid z_{i t}^{o}\right],
\end{aligned}
$$

which is finite by assumption of the theorem. Therefore, under the conditions of the theorem and by the dominated convergence theorem, the inequality in equation (D.8) is also given by

$$
E\left[\frac{1}{I E S_{i t}\left(\theta_{0}\right)} \mid z_{i t}^{o}\right] \leq \gamma_{0}-\left(1-\gamma_{0}\right) E\left[\frac{\mathcal{A}_{30}^{-1} \alpha_{0} \beta_{0} \varphi_{0 i t+1}\left(\frac{c_{i t+1}^{o}}{c_{i t}^{o \alpha_{0}}}\right)^{1-\gamma_{0}}}{1-\mathcal{A}_{30}^{-1} \alpha_{0} \beta_{0} \varphi_{0 i t+1}\left(\frac{c_{i t+1}^{o}}{c_{i t}^{o \alpha}}\right)^{1-\gamma_{0}}} \mid z_{i t}^{o}\right]-\alpha_{0}\left(1-\gamma_{0}\right) E\left[\frac{\mathcal{A}_{30}^{-1} \alpha_{0} \beta_{0} \varphi_{0 i t+2}\left(\frac{c_{i t+2}^{o}}{c_{i t+1}^{o \alpha_{0}}}\right)^{1-\gamma_{0}}}{1-\mathcal{A}_{30}^{-1} \alpha_{0} \beta_{0} \varphi_{0 i t+2}\left(\frac{c_{i t+2}^{o}}{c_{i t+1}^{o \alpha_{0}}}\right)^{1-\gamma_{0}}} \mid z_{i t}^{o}\right] .
$$


Again, by Jensen's inequality, we have $\left(E\left[1 / \operatorname{IES} S_{i t}\left(\theta_{0}\right) \mid z_{i t}^{o}\right]\right)^{-1} \leq E\left[I E S_{i t}\left(\theta_{0}\right) \mid z_{i t}^{o}\right]$ so that $E\left[I E S_{i t}\left(\theta_{0}\right) \mid z_{i t}^{o}\right] \geq\left(\gamma_{0}-\left(1-\gamma_{0}\right) E\left[\frac{\mathcal{A}_{30}^{-1} \alpha_{0} \beta_{0} \varphi_{0 i t+1}\left(\frac{c_{i t+1}^{o}}{c_{i t}^{o \alpha_{0}}}\right)^{1-\gamma_{0}}}{1-\mathcal{A}_{30}^{-1} \alpha_{0} \beta_{0} \varphi_{0 i t+1}\left(\frac{c_{i t+1}^{o}}{c_{i t}^{o \alpha}}\right)^{1-\gamma_{0}}} \mid z_{i t}^{o}\right]-\alpha_{0}\left(1-\gamma_{0}\right) E\left[\frac{\mathcal{A}_{30}^{-1} \alpha_{0} \beta_{0} \varphi_{0 i t+2}\left(\frac{c_{i t+2}^{o}}{c_{i t+1}^{o \alpha_{0}}}\right)^{1-\gamma_{0}}}{1-\mathcal{A}_{30}^{-1} \alpha_{0} \beta_{0} \varphi_{0 i t+2}\left(\frac{c_{i t+2}^{o}}{c_{i t+1}}\right)^{1-\gamma_{0}}} \mid z_{i t}^{o}\right]\right)^{-1}$.

Turning to the RRA, the individual-specific relative risk aversion is defined as

$$
R R A_{i t}=-C_{i t} \frac{\partial M U_{i t} / \partial C_{i t}}{M U_{i t}}
$$

Consequently, the risk-aversion parameters implied by our model are given by

$$
R R A_{i t}\left(\theta_{0}\right)=\frac{\gamma-(1+\alpha(1-\gamma)) \alpha \beta \varphi_{i t+1}\left(\frac{c_{i t+1}}{c_{i t}^{\alpha}}\right)^{1-\gamma}}{1-\alpha \beta \varphi_{i t+1}\left(\frac{c_{i t+1}}{c_{i t}^{\alpha}}\right)^{1-\gamma}}
$$

Because $R R A_{i t}$ is convex in $\alpha_{0} \beta_{0} \varphi_{0 i t+1}\left(c_{i t+1} / c_{i t}^{\alpha_{0}}\right)^{1-\gamma_{0}}$,

$$
\begin{gathered}
E\left[R R A_{i t}\left(\theta_{0}\right) \mid z_{i t}^{o}\right] \geq \frac{\gamma_{0}-\left(1+\alpha_{0}\left(1-\gamma_{0}\right)\right) \alpha_{0} \beta_{0} E\left[\varphi_{0 i t+1}\left(\frac{c_{i t+1}}{c_{i t}^{\alpha_{0}}}\right)^{1-\gamma_{0}} \mid z_{i t}^{o}\right]}{1-\alpha_{0} \beta_{0} E\left[\varphi_{0 i t+1}\left(\frac{c_{i t+1}}{c_{i t}^{\alpha_{0}}}\right)^{1-\gamma_{0}} \mid z_{i t}^{o}\right]} \\
=\frac{\gamma_{0}-\left(1+\alpha_{0}\left(1-\gamma_{0}\right)\right) \mathcal{A}_{30}^{-1} \alpha_{0} \beta_{0} E\left[\varphi_{0 i t+1}\left(\frac{c_{i t+1}^{o}}{c_{i t}^{o \alpha_{0}}}\right)^{1-\gamma_{0}} z_{i t}^{o}\right]}{1-\alpha_{0} \beta_{0} \mathcal{A}_{30}^{-1} E\left[\left.\varphi_{0 i t+1}\left(\frac{c_{i t+1}^{o}}{c_{i t}^{o \alpha_{0}}}\right)^{1-\gamma_{0}}\right|_{i t} ^{o}\right]} .
\end{gathered}
$$


On the other hand, using the same method and conditions as used to compute the inverse IES,

$$
\begin{aligned}
E\left[R R A_{i t}\left(\theta_{0}\right) \mid z_{i t}^{o}\right] & =\gamma_{0} \sum_{j=0}^{\infty} E\left[\left(\alpha_{0} \beta_{0} \varphi_{0 i t+1}\left(\frac{c_{i t+1}}{c_{i t}^{\alpha_{0}}}\right)^{1-\gamma_{0}}\right)^{j} \mid z_{i t}^{o}\right] \\
& -\left(1+\alpha_{0}\left(1-\gamma_{0}\right)\right) \sum_{j=1}^{\infty} E\left[\left(\alpha_{0} \beta_{0} \varphi_{0 i t+1}\left(\frac{c_{i t+1}}{c_{i t}^{\alpha_{0}}}\right)^{1-\gamma_{0}}\right)^{j} \mid z_{i t}^{o}\right] \\
& \leq \gamma_{0} \sum_{j=0}^{\infty} E\left[\left(\mathcal{A}_{30}^{-1} \alpha_{0} \beta_{0} \varphi_{i t+1}\left(\frac{c_{i t+1}^{o}}{c_{i t}^{o o \alpha_{0}}}\right)^{1-\gamma_{0}}\right)^{j} \mid z_{i t}^{o}\right] \\
& -\left(1+\alpha_{0}\left(1-\gamma_{0}\right)\right) \sum_{j=1}^{\infty} E\left[\left(\mathcal{A}_{30}^{-1} \alpha_{0} \beta_{0} \varphi_{0 i t+1}\left(\frac{c_{i t+1}^{o}}{c_{i t}^{o \alpha_{0}}}\right)^{1-\gamma_{0}}\right)^{j} \mid z_{i t}^{o}\right] \\
& =E\left[\frac{\gamma_{0}-\left(1+\alpha_{0}\left(1-\gamma_{0}\right)\right) \mathcal{A}_{30}^{-1} \alpha_{0} \beta_{0} \varphi_{0 i t+1}\left(\frac{c_{i t+1}^{o}}{c_{i t}^{o \alpha_{0}}}\right)^{1-\gamma_{0}}}{\left.1-\mathcal{A}_{30}^{-1} \alpha_{0} \beta_{0} \varphi_{0 i t+1}\left(\frac{c_{i t+1}^{o}}{c_{i t}^{o \alpha_{0}}}\right)^{1-\gamma_{0}}\right]}\right]
\end{aligned}
$$

\section{References}

Abel, A.B. (1990), “Asset Prices Under Habit Formation and Catching Up with the Jones,” American Economic Review, 80(2), 38-42.

Alan, S., and Browning, M. (2010). "Estimating Intertemporal Allocation Parameters Using Synthetic Residual Estimation," Review of Economic Studies, 77(4), 1231-1261.

Alan, S., Attanasio, O., and Browning, M. (2009), "Estimating Euler Equations with Noisy Data: Two Exact GMM Estimators,” Journal of Applied Econometrics, 24(2), 309-324.

Altug, S., and Miller, R.A. (1990), “Household Choices in Equilibrium”, Econometrica, 58(3), 543-570.

Andersen, S., Harrison, G.W., Lau, M.I., and Rutström, E.E. (2010), "Preference Heterogeneity in Experiments: Comparing the Field and Lab," Journal of Economic Behavior and Organization, 73(2), 209-224. 
Andrews, D.W.K., and Barwick, P.J. (2012), "Inference for Parameters Defined by Moment Inequalities: A Recommended Moment Selection Procedure," Econometrica, 80(6), 2805-2826.

Andrews, D.W.K., and Guggenberger, P. (2009), "Validity of Subsampling and "Plug-In Asymptotic" Inference for Parameters Defined by Moment Inequalities," Econometric Theory, 25(3), 669-709.

Andrews, D.W.K., and Shi, X. (2013), "Inference Based on Conditional Moment Inequalities," Econometrica, 81(2), 609-666.

Attanasio, O.P., Banks, J., Meghir, C., and Weber, G. (1999), "Humps and Bumps in Lifetime Consumption," Journal of Business and Economic Statistics, 17(1), 22-35.

Attanasio, O., and Low, H. (2004), "Estimating Euler Equations," Review of Economic Dynamics, $7(2), 406-435$.

Attanasio, O., and Weber, G. (1993), "Consumption Growth, the Interest Rate and Aggregation," The Review of Economic Studies, 60(3), 631-649.

Attanasio, O., and Weber, G. (1995), "Is Consumption Growth Consistent with Intertemporal Optimization? Evidence from the Consumer Expenditure Survey,' Journal of Political Economy, 103(6), 1121-1157

Banks J., Blundell, R., and Tanner, S. (1998), “Is There a Retirement Savings Puzzle?” American Economic Review, 88(4), 769-788.

Barsky, R.B., Kimball, M.S., Juster, F.T., and Shapiro, M.D. (1997), "Preference Parameters and Behavioral Heterogeneity: an Experimental Approach in the Health and Retirement Survey," Quarterly Journal of Economics, 112(2), 537-579.

Bick, A., and Choi, S. (2013), "Revisiting the Effect of Household Size on Consumption over the Life-cycle,” Journal of Economic Dynamics and Control, 37(12), 2998-3011.

Browning, M., and Collado, M.D. (2007), "Habits and Heterogeneity in Demands: a Panel Data Analysis," Journal of Applied Econometrics, 22(3), 625-640. 
Campbell, J.Y., and Cochrane, J.H. (1999), "By Force of Habit. A Consumption-based Explanation of Aggregate Stock Market Behavior,” Journal of Political Economy, 107(2), 205-251.

Carrasco, R., Labeaga, J.M., and Lopez-Salido, J.D. (2005), “Consumption and Habits: Evidence from Panel Data," The Economic Journal, 115(500), 144-165.

Carroll C.D. (2000) “Solving Consumption Models with Multiplicative Habits," Economics Letters, 68(1), 67-77.

Carroll, C.D. (2001), "Death to the Log-linearized Consumption Euler Equation! (And Very Poor Health to the Second-Order Approximation)," Advances in Macroeconomics, 1(1), 6.

Carroll, C.D., Overland J., and Weil, D.N. (2000), "Saving and Growth with Habit Formation," American Economic Review, 90(3), 341-355.

Chamberlain, G. (1984), "Panel Data," in Handbook of Econometrics, ed. Z.Griliches and M.D.Intriligator, Elsevier, 1247-1318.

Chen, X., Chernozhukov, V., Lee, S., and Newey, W.K. (2014), “Local Identification of Nonparametric and Semiparametric Models," Econometrica, 82(2), 785-809.

Chen, X., and Ludvigson, S.C. (2009), "Land of Addicts? An Empirical Investigation of HabitBased Asset Pricing Behavior,' Journal of Applied Econometrics, 24(7), 1057-1093.

Chernozhukov, V., Hong, H., and Tamer, E. (2007), "Estimation and Confidence Regions for Parameter Sets in Econometric Models," Econometrica, 75(5), 1243-1284.

Chernozhukov, V., Lee, S., and Rosen, A.M. (2013), "Intersection Bounds: Estimation and Inference," Econometrica, 81(2), 667-737.

Constantinides, G.M. (1990), "Habit Formation: A Resolution of the Equity Premium Puzzle," Journal of Political Economy, 98(3), 519-543.

Crossley, T., and Low, H. (2011), "Is the Elasticity of Intertemporal Substitution Constant?" Journal of the European Economic Association, 9(1), 87-105.

Dynan, K.E. (2000), "Habit Formation in Consumer Preferences: Evidence from Panel Data," American Economic Review, 90(3), 391-406. 
Eisenhauer, J.G., and Ventura, L. (2003), "Survey Measures of Risk Aversion and Prudence," Applied Economics, 35(13), 1477-1484.

Ferson, W.E., and Constantinides, G.M. (1991), "Habit Persistence and Durability in Aggregate Consumption: Empirical Tests," Journal of Financial Economics, 29(2), 199-240.

Fuhrer, J.C. (2000), "Habit Formation in Consumption and Its Implications for Monetary Policy Models," American Economic Review, 90(3), 367-390.

Guiso, L., and Paiella, M. (2006), "The Role of Risk Aversion in Predicting Individual Behavior," in Insurance: Theoretical Analysis and Policy Implications, ed. P.Chiappori, and C.Gollier, Boston: MIT Press.

Guvenen, F., and Smith, A. (2014), "Inferring Labor Income Risk and Partial Insurance from Economic Choices," Econometrica, 82(6), 2085-2129.

Hall, R.E. (1988), “Intertemporal Substitution in Consumption,” Journal of Political Economy, 96(2), 339-357.

Hansen, L.P., Heaton, J.C., and Yaron, A. (1996), "Finite Sample Properties of Some Alternative GMM Estimators," Journal of Business and Economic Statistics, 14(3), 262-280.

Hayashi, F. (1985), “The Permanent Income Hypothesis and Consumption Durability: Analysis Based on Japanese Panel Data," Quarterly Journal of Economics, 100(4), 1083-1113.

Heaton, J.C. (1995), “An Empirical Investigation of Asset Pricing with Temporally Dependent Preference Specifications," Econometrica, 63(3), 681-717.

Khan S., and Tamer, E. (2009), "Inference on Endogenously Censored Regression Models Using Conditional Moment Inequalities," Journal of Econometrics, 152, 104-119.

Kocherlakota, N.R. (1996), “The Equity Premium: It's Still a Puzzle,” Journal of Economic Literature, 34(1), 42-71.

Meghir, C., and Weber, G. (1996), "Intertemporal Nonseparability or Borrowing Restrictions? A Disaggregate Analysis Using a U.S. Consumption Panel,’ Econometrica, 64(5), 1151-1181. 
Muellbauer, J. (1988), "Habits, Rationality and Myopia in the Life Cycle Consumption Function," Annales d' Economie et de Statistique, 9, 47-70.

Naik, N.Y., and Moore, M.J. (1996), "Habit Formation and Intertemporal Substitution in Individual Food Consumption," Review of Economics and Statistics, 78(2), 321-328.

Newey, W.K., and McFadden, D.L. (1994), “Large Sample Estimation and Hypothesis Testing," in Handbook of Econometrics, ed. R.F. Engle, and D.L. McFadden, Elsevier.

Newey, W.K., and Powell, J.L. (2003), "Instrumental Variable Estimation of Nonparametric Models," Econometrica, 71(5), 1565-1578.

Pakoš, M. (2011), "Estimating Intertemporal and Intratemporal Substitutions When Both Income and Substitution Effects Are Present: The Role of Durable Goods," Journal of Business and Economic Statistics, 29(3), 439-454.

Romano, F.P., and Shaikh, A.M. (2008), "Inference for Identifiable Parameters in Partially Identified Econometric Models," Journal of Statistical Planning and Inference, 138, 2786-2807.

Romano, F.P., and Shaikh, A.M. (2010), "Inference for the Identified Set in Partially Identified Econometric Models," Econometrica, 78(1), 169211.

Runkle, D.E. (1991), "Liquidity Constraints and the Permanent Income Hypothesis," Journal of Monetary Economics, 27(1), 73-98.

Shapiro, M.D. (1984), “The Permanent Income Hypothesis and the Real Interest Rate,” Economics Letters, 14(1), 93-100.

Smith, W.T., and Zhang, Q. (2007), “Asset Pricing with Multiplicative Habit and Power-Expo Preferences," Economics Letters, 94(3), 319-325.

Ventura, E. (1994), “A Note on Measurement Error and Euler Equations: An Alternative to Loglinear Approximations," Economics Letters, 45(3), 305-308.

Vissing-Jorgensen, A. (2002), "Limited Asset Market Participation and the Elasticity of Intertemporal Substitution,” Journal of Political Economy, 110(4), 825-853. 